\title{
Stimulus preexposure speeds or slows subsequent acquisition of associative learning depending on learning test procedures and response measure
}

\author{
Peter C. Holland ${ }^{1}$ \\ Published online: 19 October 2017 \\ (C) Psychonomic Society, Inc. 2017
}

\begin{abstract}
Prior exposure to a conditioned stimulus (CS) typically results in latent inhibition-slower acquisition of associative learning about that stimulus in subsequent training. Here, we found that CS preexposure had different effects on the appetitive conditioning of rats with a sucrose unconditioned stimulus (US) depending on training test procedures, the similarity of preexposure and training procedures, and the choice of response measure. Preexposure to a visual or an auditory stimulus produced facilitation of acquisition of food-cup-directed responding when both of those cues were (separately) paired with sucrose delivery in the training test (Experiments 1 and 3). By contrast, the same preexposure procedure resulted in latent inhibition of food-cup learning if the second stimulus in the test phase was of the same modality as the preexposed stimulus (Experiment 2). In Experiment 3, latent inhibition was enhanced if both phases included a single CS or both phases included both auditory and visual CSs, compared to treatments in which only one CS was presented in one phase but two CSs were presented in the other phase. In Experiment 4, preexposure of an auditory cue slowed subsequent learning about it if the context was salient but enhanced learning if the context was of weaker salience. Finally, a measure of general activity revealed latent inhibition after preexposure in all conditions in all 4 experiments. We discuss the results within several classes of latent inhibition theories, none of which provides a comprehensive account.
\end{abstract}

Peter C. Holland

pch@jhu.edu

1 Johns Hopkins University, 3400 North Charles St. 200E Ames Hall, Baltimore, MD 21218, USA
Keywords Acquisition · Associative learning · Latent inhibition

Prior exposure to a conditioned stimulus (CS) often results in slowed acquisition of associative learning about that stimulus in a training test phase, a phenomenon that has come to be termed latent inhibition (e.g., Lubow \& Moore, 1959). Because the manipulation is so simple, the effects often appear to be quite substantial, and the phenomenon is observed across a range of conditioning preparations, latent inhibition has played important roles in the construction of learning theories, the exploration of brain correlates of learning, and many translational research efforts, which have identified deficits in latent inhibition in a variety of cognitive deficits and psychiatric disorders (e.g., Lubow \& Gewirtz, 1995; Lubow \& Weiner, 2010). At the same time, known limitations of the phenomenon have also played important roles in these same endeavors. For example, the observation that latent inhibition is frequently context dependent (i.e., reduced in magnitude if the preexposure and training test phases occur in different experimental contexts; e.g., Channell \& Hall, 1983; Hall \& Honey, 1989; Lovibond, Preston, \& Mackintosh, 1984) has constrained theories, influenced the search for brain correlates, and shaped translational accounts (Lubow \& Weiner, 2010). Similarly, there have been reports of boundaries to latent inhibition. For example, Rodríguez and Alonso (2004) found that the use of high magnitude unconditioned stimuli (USs) reduced the size of latent inhibition effects, and Boughner and Pepini (2003) found that preexposure to a localizable visual CS slowed the subsequent acquisition of sign-tracking (approach) responses to that cue, but did not slow acquisition of goal-tracking (food-cup entry) responses. Finally, some aspects of associative learning have been reported to be facilitated by stimulus preexposure. For example, Bonardi, Brilot, 
and Jenkins (2016) found that although CS preexposure slowed the rate of learning in a subsequent training test, it enhanced the temporal control of behavior in that test. Likewise, some investigators have found facilitation of subsequent discrimination learning after preexposure to the discriminative stimuli (e.g., Gibson \& Walk, 1956; McLaren, Kaye, \& Mackintosh, 1990), a phenomenon often termed "perceptual learning" (although that term usually refers to a much broader range of changes in perception with experience; e.g., Kellman \& Massey, 2013).

Here, we describe cases in which the same preexposure procedure produced impaired, facilitated, or unaffected subsequent learning, depending on the training test procedure, the choice of conditioned response measure, and the selection of a temporal window in which to evaluate conditioned responding. The experiments were initially derived from a procedure developed to more efficiently study the effects of selective brain lesions on reductions on stimulus associability (i.e., the ability of a cue to enter into associative learning). In those experiments, rats were given nonreinforced preexposures to one of two visual stimuli, and then received a training test in which both visual CSs were separately paired with a food US. Our reasoning was that the ability to assess preexposure effects within subjects, by comparing the rate of acquisition to the novel and preexposed CSs, would both increase the sensitivity of the index of latent inhibition (hence, reducing the number of rats needed to demonstrate lesion effects) and provide a measure of latent inhibition magnitude in each individual subject. Indeed, the procedure proved useful for confidently demonstrating the effects of some lesions (e.g., of the hippocampus and its cholinergic innervation; Baxter, Holland, \& Gallagher, 1997; Han, Gallagher, \& Holland, 1995) and the lack of effects of others (e.g., of the amygdala, Holland \& Gallagher, 1993; and substantia innominata, Chiba, Bucci, Holland, \& Gallagher, 1995).

In Experiment 1, we preexposed either a visual or an auditory stimulus and subsequently assessed acquisition of conditioned responding to both stimuli, when they were separately paired with a sucrose US. Unlike in our prior experiments that used two visual cues, with our primary response measure we found that learning about the preexposed CS was facilitated relative to learning about the novel CS. In Experiment 2, we again preexposed either the visual or auditory stimulus, but this time subsequently assessed acquisition of conditioned responding in a training test in which the preexposed CS and another CS of the same modality were separately paired with the sucrose US. In that experiment, we found substantial latent inhibition. In Experiment 3, we examined the effects of preexposing either an auditory stimulus alone or both an auditory and a visual stimulus on subsequent learning in a training test that included either the auditory stimulus alone or both the auditory and visual CSs. We found that latent inhibition was larger when the conditions of preexposure and test training were similar, and we found facilitation when, as in Experiment 1, only the auditory stimulus was preexposed but both CSs were trained in the test phase. Finally, in Experiment 4 , we examined the effects of context salience in a standard latent inhibition procedure in which rats received preexposure and a training test with a single cue. We found latent inhibition when the context was salient and facilitation when it was of low salience. In many cases, the conclusions about preexposure effects depended on the choice of response measure and whether responding was viewed early or late in the CS-US interval.

\section{General methods}

\section{Subjects}

The subjects in these experiments were experimentally naïve Long-Evans or Charles River CD strain rats obtained from Charles River Laboratories (Raleigh, NC), weighing between 300 and 325 grams when they arrived in the laboratory vivarium. The rats were housed individually and given a 1-week acclimatization period to adjust to their new surroundings and to being handled by the experimenter on a daily basis. During this period, the rats had free access to food and water. Thereafter, their access to food was restricted to maintain $85 \%$ of their ad libitum weights. The vivarium was illuminated from 7 a.m. to 7 p.m. Some experiments and replications were conducted at Duke University and some at Johns Hopkins University. The care and experimental treatment of the rats was conducted according to the National Institutes of Health's Guide for the Care and Use of Laboratory Animals, and was approved by Institutional Animal Care and Use Committees at each of those universities.

\section{Apparatus}

The behavioral training apparatus consisted of eight individual chambers $(22.9 \mathrm{~cm} \times 20.3 \mathrm{~cm} \times 20.3 \mathrm{~cm})$ with aluminum front and back walls, clear acrylic sides and top, and a floor made of $0.48 \mathrm{~cm}$ stainless steel rods spaced $1.9 \mathrm{~cm}$ apart. A dimly illuminated food cup was recessed in the center of one end wall. A 6-W jeweled panel light, which served as the source of one visual CS, was located $5 \mathrm{~cm}$ above the opening to the food-cup recess. An infrared photocell placed inside the food cup was used to register food-cup entries and the amount of time spent in the cup. Liquid sucrose could be delivered to the food cup by activating a solenoid valve mounted on the chamber's outside wall, above the food cup. Activation of the valve produced a loud click. An infrared activity monitor (Model H24-61, Coulborn Instruments, Allentown, PA) was mounted on the top of each chamber. Each chamber was enclosed in a sound-attenuating shell, in which ventilation 
fans provided masking noise (72 dB). A speaker, used to present auditory CSs, which included a 78-dB 1500-Hz tone, a 74$\mathrm{db} 300-\mathrm{Hz}$ intermittent $(3 \mathrm{~Hz}$ ) tone, and a $78-\mathrm{dB}$ white noise, was mounted on the inside wall of the shell, $5 \mathrm{~cm}$ above and $20 \mathrm{~cm}$ to the left of the panel light. A second 6-W lamp, which was the source of a second visual CS, was mounted just to the left of the speaker. The same apparatus was used in all experiments and replications.

\section{Behavioral training procedures}

All experiments began with an initial preexposure phase in which rats received nonreinforced cue presentations or placement in the experimental chambers in the absence of explicit cue presentations. Next, rats were trained to enter the liquid cup and consume the liquid sucrose US. Finally, rats received pairings of one or more CSs with the sucrose US.

\section{Response measures and data analysis}

The critical data of these experiments were those from the CSUS training phase of each study. We reported three automated measures of conditioning to the various CSs, including the time spent in the food cup, expressed as a percentage of cue sample duration, the rate of food-cup entries, and the rate of activity counts. Because previous studies (Holland, 1977, 1980) showed that these measures can be distributed differently across time, we reported them separately for three sampling intervals: the first half of each 10-s CS, the last half of each 10-s CS, and the 5-s (pre-CS) period immediately prior to each CS presentation.

Separate mixed analyses of variance (ANOVAs) were conducted for each sample interval, for each measure. Betweensubject variables included whether a cue was preexposed or not, the identity of the preexposed cue (or cues), and (in some cases) replication and/or sex of the subject. Within-subjects variables included session, and in some cases, type of trial within each session. In some experiments, the effects of CS preexposure were assessed between-subjects, and in others it was assessed both between-subjects and within-subjects. Planned contrasts that evaluated specific hypotheses are described in each experiment. Preliminary ANOVAs that included replication and/or sex as between-subjects variables showed no significant effects or interactions involving those variables, so they are not included in the analyses we reported. Effect sizes are given as partial eta squared $\left(\eta^{2}\right)$, and the level of significance adopted was $p<.05$.

\section{Experiment 1}

In Experiment 1, rats received preexposure to either a visual (V) or an auditory (A) stimulus, prior to reinforced training with both of those CSs. Because we anticipated little or no generalization of learning established in either the preexposure or training test phases between the auditory and visual CS, we expected this procedure to yield especially large latent inhibition effects compared to our prior studies, in which the magnitude of the within-subjects latent inhibition effect might be reduced by generalization between the two intramodal cues. Unexpectedly, we found that although stimulus preexposure reduced general activity in response to those cues after their pairing with food, it facilitated acquisition of a measure of food-cup entry.

\section{Method}

Twenty male Long-Evans rats served as subjects, 16 at Duke and four at Johns Hopkins. Table 1 shows an outline of the procedures of Experiment 1. The rats first received 10 daily 64-min preexposure sessions, each of which included eight 10-s presentations of either a $1500-\mathrm{Hz}$ tone CS (Group A) or illumination of the panel light CS (Group V), with random intertrial intervals (ITIs; mean $=4 \mathrm{~min}$, range: $2-8 \mathrm{~min}$ ). In each replication, equal numbers of rats were preexposed to each stimulus. Next, the rats were trained to enter the food cups and consume the reinforcer that was used throughout this and all subsequent experiments, the delivery of $0.3 \mathrm{ml}$ of $0.2 \mathrm{M}$ liquid sucrose. In each of two 64-min sessions, 16 sucrose deliveries were made at random times, with a mean ITI of $4 \mathrm{~min}$, within a range of 2-8 min. Finally, all rats received a training test with pairings of both the auditory and visual CSs. In each of five 64-min sessions, each rat received four pairings of each of the panel light and tone CSs with delivery of the sucrose US, randomly intermixed.

\section{Results}

Figure 1 shows activity counts over the course of the preexposure phase in Experiment 1. Activity levels declined over sessions for all three sampling intervals, main effects of sessions, $F_{\mathrm{S}}(9,162)>4.57, p \mathrm{~s}<.001, \eta^{2} \mathrm{~s}>.202$. Pre-CS activity did not differ between Groups A and V, (main effect of group $F<1, p=.403$ ), but activity during the visual CS was higher than that during the auditory CS in both the first, $F(1$, $18)=6.54, p=.020, \eta^{2}=.267$, and the last $F(1,18)=31.85, p$ $<.001, \eta^{2}=.639$, halves of the 10 -s CS presentations. None of the Group $\times$ Sessions interactions was significant $\left(F_{\mathrm{S}}<1.04\right.$, ps >.414).

Figure 2 shows the effects of CS preexposure on conditioning in the training test of Experiment 1. These effects differed depending on the measure and sampling interval. Consider first the time in food-cup measure (Fig. 2a-c), the measure we have reported most often in past studies. Previous studies have shown that the time spent in the food cup increases as the time of US delivery approaches (Holland, 1977, 1980), and that the proportion of time spent in the food cup during the last 

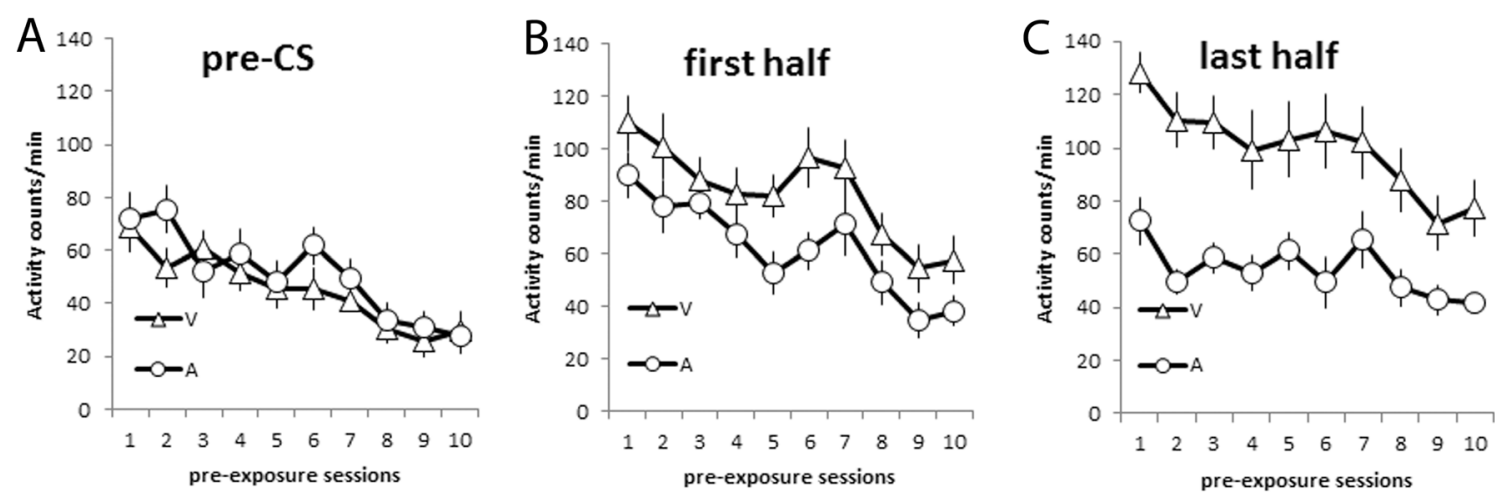

Fig. 1 Mean $( \pm S E M)$ activity responding in the preexposure phase of Experiment 1. Rats in Group V received preexposure presentations of a visual stimulus, and rats in Group A received presentations of an auditory

stimulus. Panels $\mathrm{a}, \mathrm{b}$, and $\mathrm{c}$ show responding during the $5 \mathrm{~s}$ prior to stimulus presentations, the first $5 \mathrm{~s}$ of the stimulus, and the last $5 \mathrm{~s}$ of the stimulus, respectively

$5 \mathrm{~s}$ of 10 -s CSs provides the most consistent measure of conditioning.

Figure 2c shows food-cup time during the last half of the 10 -s CS-US interval. Conditioning to both the visual (dotted lines) and auditory (solid lines) CSs was more rapid in rats that received preexposure (open symbols) of those cues than in those rats that did not (filled symbols). That is, preexposure of a cue facilitated acquisition of food cup responding to it. A Group (Avs. V) $\times$ Test Cue (preexposed vs. nonpreexposed) $\times$ Sessions ANOVA showed significant effects of sessions, $F(4$, $72)=20.01, p<.001, \eta^{2}=.526$, and of cue, $F(1,18)=34.71$, $p<.001, \eta^{2}=.659$, reflecting more conditioning to preexposed than to nonpreexposed cues. Planned individual between-subjects contrasts showed significantly $(p=.012)$ more responding to the auditory cue in Group A (in which it was preexposed) than in Group V (in which it was not), and significantly $(p=.042)$ more responding to the visual CS in Group V (in which it was preexposed) than in Group A. Furthermore, it is worth noting that the main effect of cue and each of the between-subjects facilitation effects were also significant within the first replication alone, and all four rats in the second replication showed more test responding to the preexposed than to the nonpreexposed cue. (The intent of the replication was not to add observations to an otherwise insignificant effect, but instead to determine if the original effect was still obtainable at a new site, where additional research was to be conducted.)

Returning to the primary Group $\times$ Cue $\times$ Sessions ANOVA, the Group $\times$ Cue interaction was also significant, $F(1,18)=30.31, p<.001, \eta^{2}=.627$. This interaction indicated greater responding to the auditory CS than to the visual CS, regardless of preexposure treatment; that is, in Group A, responding was greater to the preexposed (auditory) CS, whereas in Group V, responding was greater to the nonpreexposed (auditory) CS. Because the rats acquired more responding to the auditory CS than to the visual CS, assessment of preexposure effects within each group is difficult. Although Group A showed significantly more rapid conditioning to the preexposed auditory cue than to the visual cue $(p<.001)$ that difference could reflect a facilitatory effect of preexposure or simply more rapid conditioning to the auditory cue. Similarly, although conditioning to the auditory and visual cues did not differ within Group V $(p=.788)$, the overall more rapid conditioning of auditory cues may have concealed a preexposure facilitation effect for the visual cue, as suggested by the between-groups comparison.

Figure $2 b$ shows food-cup time during the first half of the CS interval. As with last half food-cup time, ANOVA showed a significant effect of cue, $F(1,18)=15.03, p=.001, \eta^{2}=.455$, favoring the preexposed cue, as well as a significant Group $\times$ Cue interaction, $F(1,18)=35.27, p<.001, \eta^{2}=.662$, and a significant effect of sessions, $F(4,72)=8.82, p<.001, \eta^{2}=$ .329. However, although a between-subject contrast showed a preexposure facilitation effect for the auditory CS, that is, significantly $(p=.026)$ more conditioning to the auditory cue (solid lines) in Group A than in Group V, a similar contrast showed no significant $(p=.171$ ) difference in responding to the visual cue (dotted lines) between groups. As with last half time, the within-subject comparison suggested a significant preexposure facilitation in Group A $(p<.001)$, but rats in Group V showed no such difference $(p=.162)$. Finally, ANOVA of food-cup times in the pre-CS periods (Fig. 2a) showed no significant effects or interactions ( $p \mathrm{~s}>.156$ ).

Figure $2 \mathrm{~d}-\mathrm{f}$ show the rates of food-cup entry during the training test of Experiment 1. This measure showed only slight evidence for preexposure facilitation. Figure $2 \mathrm{f}$ shows entry rates during the last half of the CS intervals. Unlike with food-cup time, the main effect of cue was not significant, $F(1$, 18) $=3.33, p=.085, \eta^{2}=.156$, although the Cue $\times$ Group interaction, suggesting a superiority of the auditory cue independent of preexposure, was significant, $F(1,18)=15.027$, $p$ $=.001, \eta^{2}=.455$, as was the effect of sessions, $F(4,72)=$ 38.11, $p<.001, \eta^{2}=.679$. Individual contrasts showed a marginally significant between-subjects preexposure facilitation effect for the visual $(p=.063)$ cue, but no such effect for the auditory cue $(p=.720)$. Figure 2e shows food cup entry 

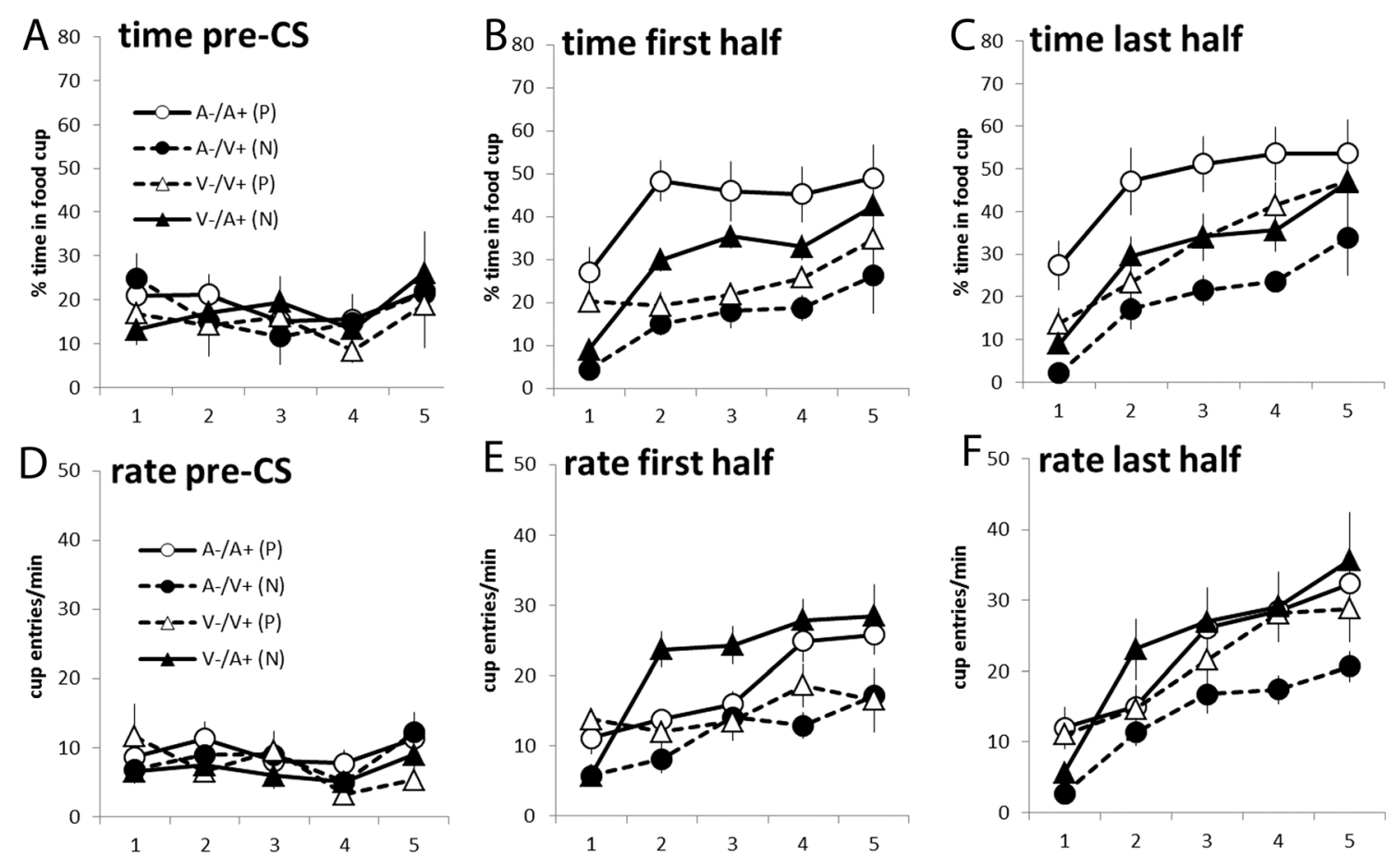

$\mathrm{F}_{50}$ rate last half
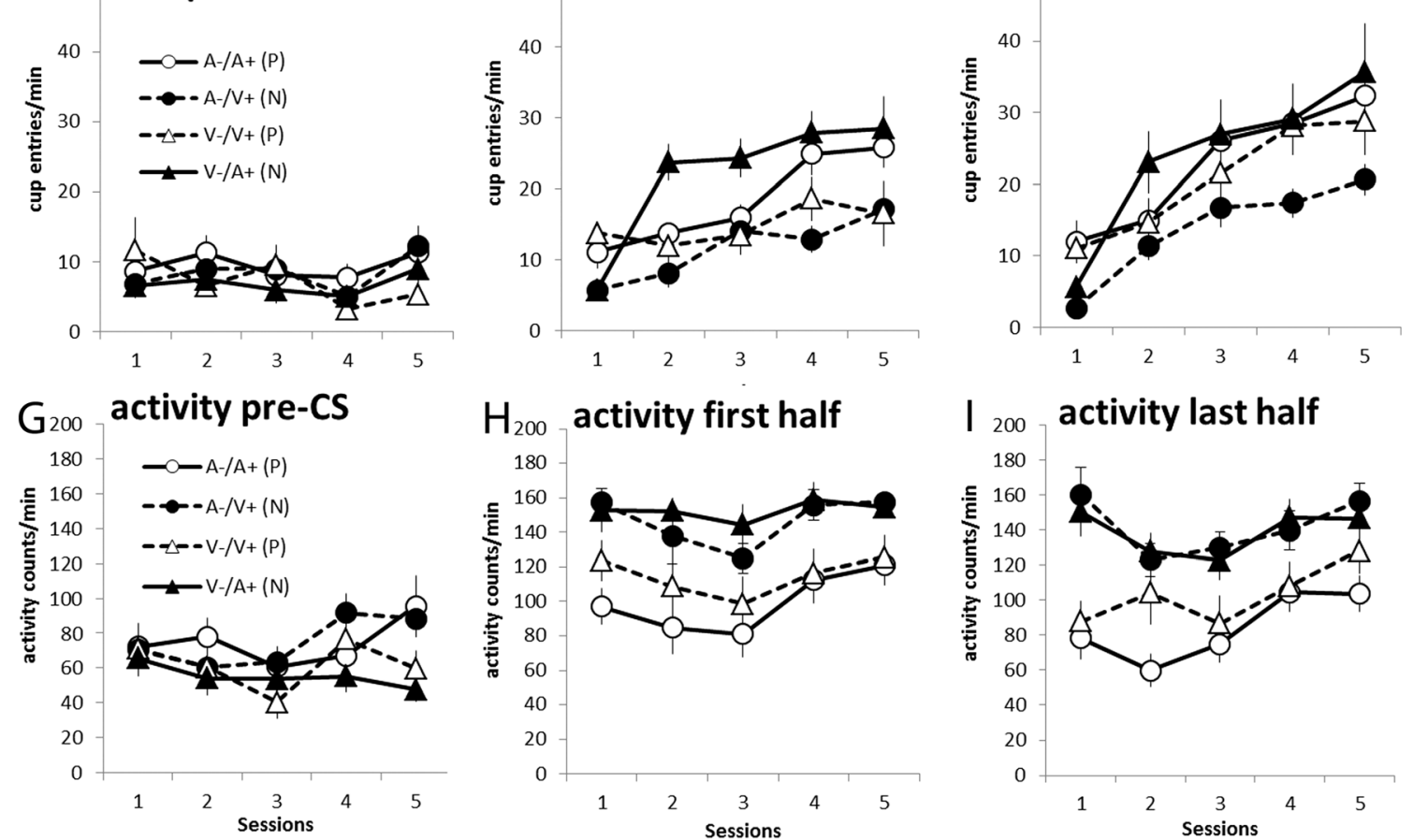

Fig. 2 Mean $( \pm S E M)$ responding during the reinforced training test phase of Experiment 1. Points labeled $\mathrm{A}-\mathrm{A}+(\mathrm{P})$ refer to responding to the preexposed auditory stimulus in Group $\mathrm{A} ; \mathrm{A}-/ \mathrm{V}+(\mathrm{N})$ to the nonpreexposed visual stimulus in Group $\mathrm{A} ; \mathrm{V}-/ \mathrm{V}+(\mathrm{P})$ to the preexposed visual stimulus in Group $\mathrm{V}$; and $\mathrm{V}-/ \mathrm{A}+(\mathrm{N})$ to the nonpreexposed auditory stimulus in Group A. Circles refer to responding in Group A, triangles to responding in Group V, open symbols to responding to the preexposed stimulus, filled symbols to

responding to the nonpreexposed stimulus, solid lines to responding to the auditory stimulus, and dotted lines to responding to the visual stimulus. Panels a-c show percentage time in the food cup, panels $\mathrm{d}-\mathrm{f}$ show food cup entry rates, and panels g-i show activity counts. Panels a, $\mathrm{d}$, and $\mathrm{g}$ show responding in the $5 \mathrm{~s}$ prior to stimulus presentations, panels $\mathrm{b}$, e, and $\mathrm{h}$ show responding during the first $5 \mathrm{~s}$ of each stimulus, and panels $\mathrm{c}, \mathrm{f}$, and i show responding during the last $5 \mathrm{~s}$ of each stimulus

rates during the first half of the CS intervals. As with the last half data, the main effect of cue was not significant $(F<1, p=$ .809), nor were the individual between-groups contrasts for conditioning of the auditory $(p=.168)$ or visual $(p=.122)$ cues. Similarly, the Cue $\times$ Group interaction, indicating overall superiority of the auditory CS, $F(1,18)=65.56, p<.001$, $\eta^{2}=.785$, and the main effect of sessions, $F(4,72)=17.33, p$ $<.001, \eta^{2}=.491$, were both significant. Finally, ANOVA of pre-CS food cup entry rates (Fig. 2d) revealed no significant main effects or interactions ( $p s>.293)$ except for a marginally significant effect of sessions, $F(4,72)=2.37, p=.060, \eta^{2}=$ .116 .
Figure $2 \mathrm{~g}-\mathrm{i}$ show activity counts during the training test of Experiment 1 . This measure typically reflects conditioned orienting to the $\mathrm{CS}$ and/or approach to the food cup, and tends to occur at the highest rate, but with the least variance, during the initial portions of the CS-US interval. Unlike the food-cup measures, activity showed unequivocal evidence for latent inhibition. For each of the first (Fig. 2h) and last (Fig. 2i) halves of the CS interval, the main effect of cue was significant, $F \mathrm{~s}(1,8)>18.70, p \mathrm{~s}<.001, \eta^{2} \mathrm{~s}>.509$, and individual between-group comparisons for both the auditory and visual CSs showed significantly greater responding to the nonpreexposed CS than to the preexposed CS $(p s<.025)$. 
Furthermore, even the within-subjects comparisons in both Group A $(p s<.003)$ and Group V $(p s<.023)$ showed significantly more responding to the nonpreexposed cue. Notably, these comparisons were feasible because unlike with the food cup measures, there was no evidence for overall superiority of the auditory cue in conditioning of activity responding, $F_{\mathrm{S}}(1$, $18)<1.15, p s>.298$ ); recall that the levels of unconditioned activity were higher for the visual CS in the preexposure phase. The effect of sessions was significant in both halves of the CS interval, $F_{\mathrm{S}}(4,72)>11.98, p \mathrm{~s}<.001, \eta^{2} \mathrm{~s}>.399$, but did not reflect a simple monotonic learning function (see Discussion). Finally, ANOVA of pre-CS activity (Fig. 2g) showed only a significant main effect of sessions, $F(4,72)=$ $3.32, p=.015, \eta^{2}=.156$, and a significant Group $\times$ Cue $\times$ Sessions interaction, $F(4,72)=4.19, p=.004, \eta^{2}=.189$, neither of which appeared systematic.

\section{Discussion}

In this experiment, we examined the effects of preexposing either a visual or an auditory stimulus on subsequent conditioning to both of those cues in a training test. With the measure of conditioning most commonly reported in my laboratory, the time spent in the food cup during cue presentations, preexposure to either stimulus facilitated acquisition of conditioned responding to that stimulus in the training test, compared to the learning performance of rats that had been preexposed to the other cue. By contrast, with another measure of food-based conditioning reported by many investigators, the rate of food-cup entry, the effects of preexposure were equivocal, with slowed learning (latent inhibition) visible for the visual cue in the first half of the CS-US interval and facilitation apparent for the auditory cue in the last half. Finally, the general activity response was consistently more prevalent to the nonpreexposed cue than to the preexposed cue, indicative of latent inhibition.

It is important to note that, as in most investigations of preexposure effects, we did not provide controls for the occurrence of learning (cf. Boughner \& Papini, 2003). That is, although we compared learning to preexposed and nonpreexposed cues, we did not examine the effects of preexposure on responding that was not attributable to new learning. In the case of the two food-cup measures, it is unlikely that this lack of learning controls poses an interpretative problem: Those measures showed clear acquisition effects, occurred at considerably higher than baseline levels, and are unlikely to occur in the absence of learning about food delivery. However, the activity measure poses potential interpretative problems. First, activity during the novel CSs did not show consistent acquisition functions. Instead, activity to both novel cues started at high levels and was maintained at those levels throughout conditioning. Previous experiments suggest that this pattern of maintenance of unconditioned activity to a cue after pairings with food is not unusual and reflects sensitivity to the CS-US relation, despite the lack of an acquisition function (e.g., Groshek et al., 2005; see Rescorla, 1988). Notably, in the absence of CS-US pairings, activity to the CSs would decline to levels comparable to those observed at the end of the preexposure phase. Nevertheless, for the most part, the lower levels of responding to the preexposed cues in testing reflected a lower starting point, likely due to the habituation of unconditioned cue-elicited activity in the preexposure phase. Thus, the "latent inhibition" effect observed with the activity measure might better be described as the result of habituation of unconditioned orienting responses (ORs) and other responses to the CSs prior to conditioning. We considered this possibility in more depth in the General Discussion.

\section{Experiment 2}

The results of Experiment 1 are surprising, given our previous use of a very similar procedure to produce latent inhibition effects. Baxter et al., (1997), Chiba et al., (1995), Han et al., (1995), and Holland and Gallagher (1993) preexposed the same panel light cue and then administered a training test in which both that cue and another visual cue were separately paired with food. Except in brain-damaged rats, in those experiments we uniformly found slowed acquisition of foodcup-directed behaviors to the preexposed cue, suggesting that something about adding an auditory cue rather than another visual cue to the training test encouraged facilitation rather than latent inhibition. In Experiment 2, we examined the effects of preexposure of visual or auditory CSs on conditioning when the two CSs trained in the test phase were within the same modality. In Experiment 2a, we examined the effects of preexposing either the panel light or house light cues prior to a reinforced training test with both of those cues, and in Experiment 2b, we examined the effects of preexposing either the $1500-\mathrm{Hz}$ tone used in Experiment 1 or a $400-\mathrm{Hz}$ tone prior to a reinforced training test that included both of them.

\section{Method}

The subjects were Long-Evans male rats, 20 in Experiment $2 \mathrm{a}$ (in two replications) and 16 in Experiment 2b. All replications were conducted at Duke University. The apparatus was the same as that used in Experiment 1.

Table 1 shows an outline of the procedures of Experiment 2. The rats first received ten 64-min preexposure sessions, each of which included eight nonreinforced 10 -s presentations of either the panel light CS used in Experiment 1 or a 10-s intermittent $(3 \mathrm{~Hz}$ ) house light (Experiment $2 \mathrm{a}$ ) or of either the $1500-\mathrm{Hz}$ tone used in Experiment 1 or an intermittent $(3 \mathrm{~Hz})$ $400-\mathrm{Hz}$ tone (Experiment 2b). Next, the rats received food-cup 

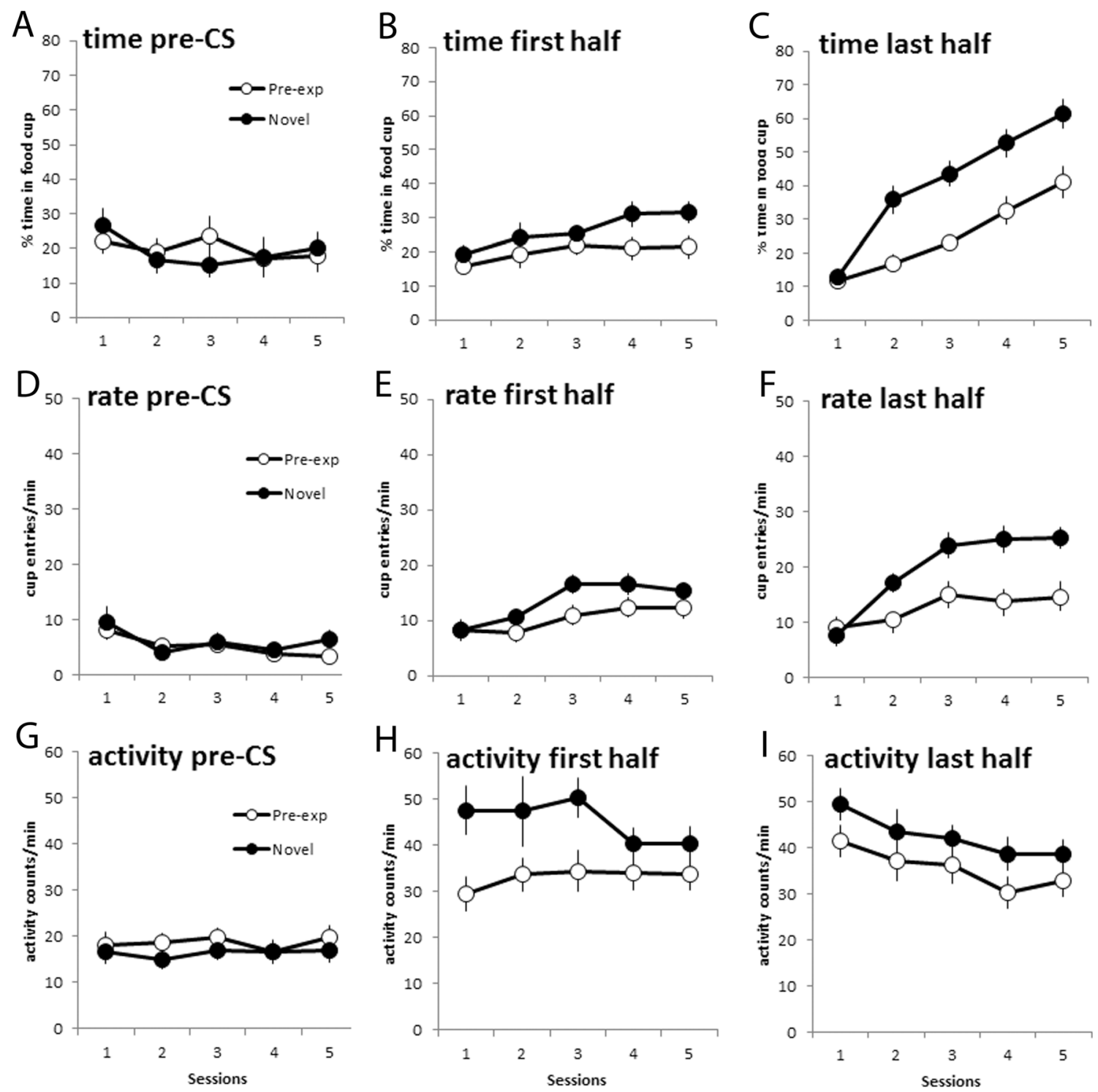

Fig. 3 Mean $( \pm S E M)$ responding during the training test phase of Experiment 2a. Points labeled Pre-exp refer to responding to the preexposed visual cue, and those labeled Novel refer to responding to the other visual stimulus, which was presented for the first time in the training test. Panels a-c show percentage time in the food cup, panels $\mathrm{d}-\mathrm{f}$ show food cup entry rates, and panels g-i show activity counts. Panels a, $\mathrm{d}$, and $\mathrm{g}$ show responding in the $5 \mathrm{~s}$ prior to stimulus presentations, panels $\mathrm{b}$, e, and $\mathrm{h}$ show responding during the first $5 \mathrm{~s}$ of each stimulus, and panels $\mathrm{c}, \mathrm{f}$, and $\mathrm{i}$ show responding during the last $5 \mathrm{~s}$ of each stimulus training as in Experiment 1, followed by five 64-min training test sessions that included either four reinforced panel-light CSs and four reinforced house-light CSs (Experiment 2a), or four reinforced $1500-\mathrm{Hz}$ tone CSs and four reinforced $400-\mathrm{Hz}$ tone CSs (Experiment 2b), randomly intermixed.

\section{Experiment 2a results}

In the preexposure phase, activity during both CS periods and the pre-CS period declined over sessions, $F_{\mathrm{S}}(9,162)>11.24$, $p \mathrm{~s}<.001, \eta^{2} \mathrm{~s}>.384$. On the final session, activity counts $/ \mathrm{min}$ were $8.0 \pm .5,10.7 \pm .8$, and $11.4 \pm .7$, in the pre-CS, first, and last half periods of the visual cues. The identity of the visual cue had no significant effects or interactions $(F \mathrm{~s}<1, p \mathrm{~s}>$ .233).

Figure 3 shows the results of the training test in Experiment 2a. Latent inhibition was observed for all measures. Unlike in Experiment 1, Preexposure Cue Identity (house light vs. panel light; akin to the group variable in Experiment 1) $\times$ Test Cue (preexposed vs. nonpreexposed) $\times$ Sessions ANOVAs showed no significant effects of preexposure cue identity or interactions involving that variable $(p s>.232)$. Figure $3 \mathrm{c}$ shows time in the food cup in the last half of the CS intervals. Conditioning was greater to the nonpreexposed cue; the main effect of cue, $F(1,18)=30.19, p<.001, \eta^{2}=.626$, was significant, as was the effect of sessions, $F(4,72)=50.59, p$ 
$<.001, \eta^{2}=.738$, and the Cue $\times$ Sessions interaction, $F(4,12)$ $=14.66, p<.001, \eta^{2}=.449$. Furthermore, the within-subjects comparisons were significant for both rats preexposed to the house light and those preexposed to the panel light $(p s<.003)$, as were the between-subjects comparisons of responding to each of those cues $(p s<.045)$. Figure $3 \mathrm{~b}$ shows time in the food cup during the first half of the CS intervals; again, latent inhibition was observed, although the effect was considerably smaller. The main effect of cue was significant, $F(1,18)=$ $7.86, p=.012, \eta^{2}=.304$, as was the effect of sessions, $F(4$, $72)=3.17, p=.019, \eta^{2}=.150$. The within-subjects latent inhibition effect was significant when the panel light had been preexposed $(p=.021)$ but not when the house light was preexposed $(p=.282)$; however, a between-subjects comparison showed more responding to the house light when it was novel than when it was preexposed $(p=.011)$. Finally, ANOVA showed no significant effects or interactions for food-cup times during the pre-CS (Fig. 3a) intervals ( $p s>$ .187).

Figure $3 \mathrm{~d}-\mathrm{f}$ show the rates of food-cup entries in the training test of Experiment 2a. As with time in the food cup, substantial latent inhibition was observed during the second half of the CS interval, and lesser amounts in the first half. For the second half (Fig. 3f), ANOVA showed significant effects of cue, $F(1,18)=14.57, p=.001, \eta^{2}=.447$, and sessions $F(4$, $72)=15.17, p<.001, \eta^{2}=.457$, and a significant Cue $\times$ Sessions interaction, $F(4,72)=11.36, p<.001, \eta^{2}=.387$. Contrasts of within-subjects latent inhibition for each cue counterbalancing condition were significant $(p s<.050)$, as was the between-subjects comparison of responding to the panel light $(p=.028)$. For the first half of the CS (Fig. 3e), the effects of cue, $F(1,18)=7.21, p=.015, \eta^{2}=.286$, and sessions, $F(4,72)=8.53, p<.001, \eta^{2}=.322$, were significant, but only the within-subjects comparison of responding to the preexposed panel light and nonpreexposed house light was significant $(p=.014)$. Finally, ANOVA of pre-CS food-cup entry rates (Fig. $3 \mathrm{~d}$ ) showed no significant effects or interactions $(p s>.079)$.

Figure $3 \mathrm{~g}-\mathrm{i}$ show activity responding in the training test of Experiment 2a. Latent inhibition was evident in both CS periods. For responding in the first half of the cues (Fig. $3 \mathrm{~h})$, ANOVA showed significant effects of cue, $F(1,8)=$ $16.80, p<.001, \eta^{2}=.483$, and sessions, $F(4,72)=2.78, p$ $=.033, \eta^{2}=.134$, and both within-subjects contrasts of latent inhibition were significant $(p s<.026)$. In the last half of the CS period (Fig. 3i), only the main effect of cue, $F(1,18)=9.07, p=.007, \eta^{2}=.335$, was significant. The rats that were preexposed to the panel light showed significant $(p=.030)$ latent inhibition within subjects, but that effect was of only marginal significance in the rats that received preexposure of the house light $(p=.072)$. Finally, ANOVA of pre-CS activity (Fig. 3g) showed no significant main effects or interactions ( $p \mathrm{~s}>.165)$.

\section{Experiment 2b results}

Activity responding decreased over the course of the preexposure phase, although that decrease was significant only in the pre-CS period, $\left(F(7,98)=2.71, p=.013, \eta^{2}=.162\right.$; other $p s>.131$. On the final session, activity counts/min were $34.7 \pm 4.5,36.6 \pm 3.6$, and $34.6 \pm 4.6$ in the pre-CS interval, and the first and last halves of the auditory CSs, respectively.

Figure 4 shows conditioning to the auditory CSs in the training test of Experiment $2 b$. For the time in food-cup measure, latent inhibition was substantial in both CS periods (Fig. $4 \mathrm{~b}-\mathrm{c})$. ANOVAs showed significant effects of cue, $F \mathrm{~s}(1,14)<$ $30.27, p \mathrm{~s}<.001, \eta^{2} \mathrm{~s}>.683$, and sessions, $F_{\mathrm{s}}(4,56)>8.65, p \mathrm{~s}$ $<.001, \eta^{2} \mathrm{~s}>.381$, and within-subjects contrasts of the latent inhibition effect were significant for each preexposure condition $(p s<.006)$. ANOVA of pre-CS time in the food cup (Fig. 4a) showed only a significant effect of sessions, $F(4,56)=$ $3.40, p=.015, \eta^{2}=.195$.

There was only minimal evidence for latent inhibition with the food-cup entry-rate measure. For both first and last halves of the CS interval (Fig. 4e-f), ANOVAs showed insignificant effects of cue, $F_{\mathrm{s}}(1,14)<1.39, p \mathrm{~s}>.257, \eta^{2} \mathrm{~s}<.090$. In both cases, the effect of sessions, $F_{\mathrm{s}}(4,56)>21.86, p \mathrm{~s}<.001, \eta^{2} \mathrm{~s}$ $>.609$, and the Cue $\times$ Sessions interaction were significant, $F_{\mathrm{s}}(4,56)>2.78, p \mathrm{~s}<.035, \eta^{2} \mathrm{~s}>.166$, suggesting a slight latent inhibition effect in the initial sessions. Indeed, for both time intervals, contrasts of the (decreasing) linear trend in the difference between entry rates to the nonpreexposed and preexposed cues were significant $(p s<.002)$. ANOVA of pre-CS food-cup entry rates (Fig. 4d) showed only a significant effect of sessions, $F(4,56)=3.13, p=.021, \eta^{2}=.183$.

With the activity measure, latent inhibition was evident in each half of the CS interval (Fig. 4h-i). ANOVAs showed significant effects of cue, $F_{\mathrm{S}}(1,14)>16.87, p \mathrm{~s}<.002, \eta^{2} \mathrm{~s}>$ .546 , and session, $F_{\mathrm{s}}(4,56)>19.40, p \mathrm{~s}<.001, \eta^{2} \mathrm{~s}>.580$. Within-subjects contrasts of latent inhibition were significant for both preexposure conditions in the first half (Fig. 4; $p$ s $<$ .010 ), but only for the rats preexposed to the $400-\mathrm{Hz}$ tone ( $p<$ .001 ) in the last half (Fig. 4i). However, the between-subjects comparisons of latent inhibition were significant for both auditory stimuli in that period $(p \mathrm{~s}<.035)$.

\section{Discussion}

As in previous studies (Baxter et al., 1997; Chiba et al., 1995; Han et al., 1995; Holland \& Gallagher, 1993), when the training test procedure included two CSs of the same modality cues, latent inhibition was observed for both visual and auditory CSs, even though the identical preexposure conditions led to facilitation (with the time in food-cup measure) in Experiment 1, in which one auditory and one visual CS were presented in the training test. 

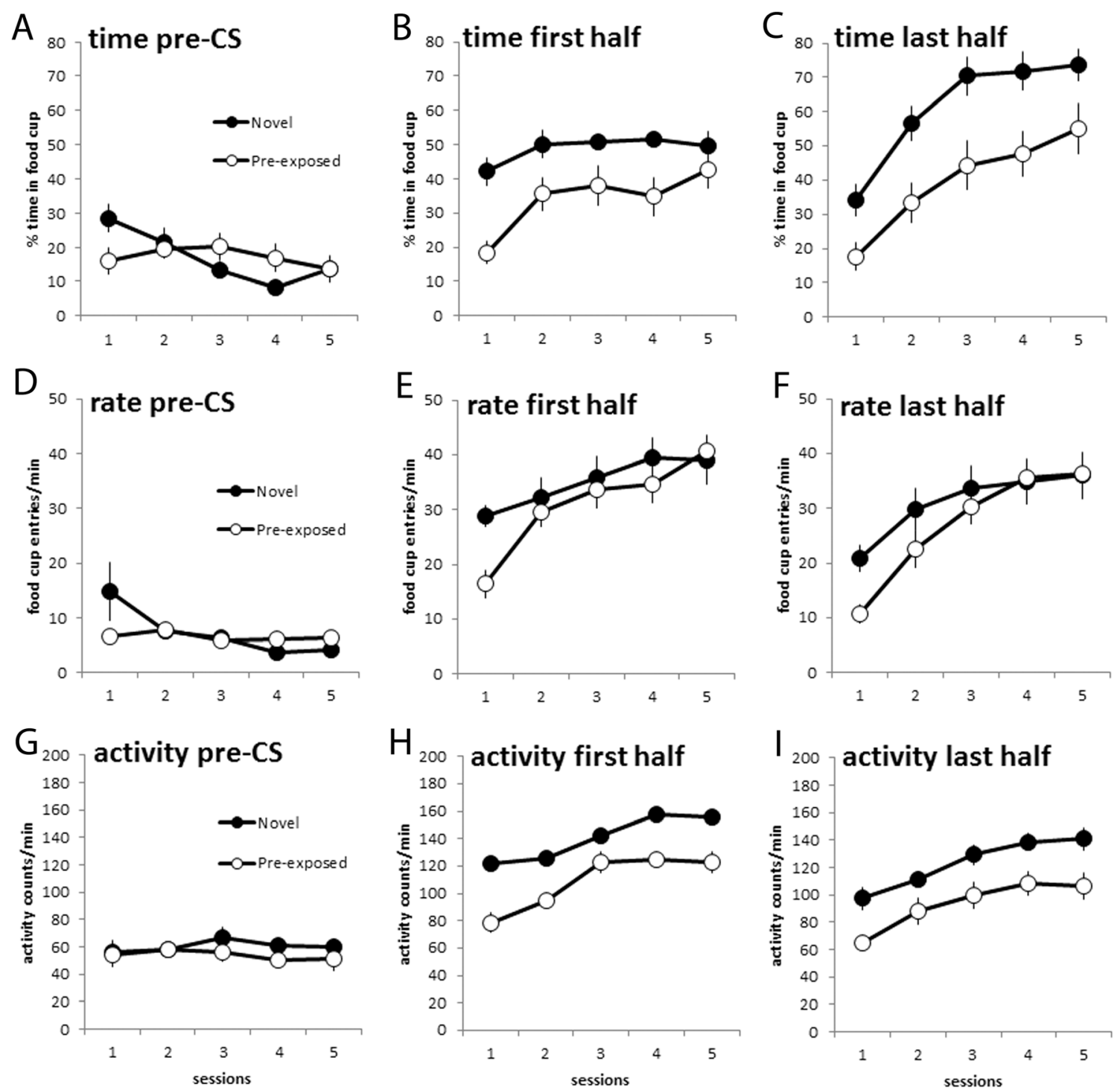

Fig. 4 Mean $( \pm S E M)$ responding during the training test phase of Experiment $2 b$. Points labeled Pre-exposed refer to responding to the preexposed auditory cue, and those labeled Novel refer to responding to the other auditory stimulus, which was presented for the first time in the training test. Panels a-c show percentage time in the food cup, panels $d-f$

show food cup entry rates, and panels g-i show activity counts. Panels a, $\mathrm{d}$, and $\mathrm{g}$ show responding in the $5 \mathrm{~s}$ prior to stimulus presentations, panels $\mathrm{b}$, e, and h show responding during the first $5 \mathrm{~s}$ of each stimulus, and panels $\mathrm{c}, \mathrm{f}$, and $\mathrm{i}$ show responding during the last $5 \mathrm{~s}$ of each stimulus

In Experiment 2a, the latent inhibition effect with the foodcup measures was much smaller in the first half of the visual CSs than in the last half. However, this difference is confounded with the overall lower levels of responding observed in the first interval. Notably, in Experiment 2b, the latent inhibition effects with auditory CSs were more commensurate in the two intervals, as were the overall levels of conditioned responding. This difference in the temporal distribution of food-cup responding is consistent with previous studies of conditioned responding to visual and auditory CSs. The first half of 10-s visual CS responding is often dominated by visual ORs, such as rearing, whereas the typical auditory OR is a startle response, which occupies only a second or two at CS onset (e.g., Holland, 1977), followed by approach to the food cup.
The patterns of activity responding observed in these experiments differed from those observed in Experiment 1. In both Experiments $2 \mathrm{a}$ and $2 \mathrm{~b}$, activity during the CS intervals was considerably greater than baseline activity, and in Experiment $2 b$, activity during each CS interval showed obvious acquisition functions. We consider these differences in the General Discussion.

Finally, in an unpublished experiment, we extended the generality of Experiment 2 by examining the effects of different amounts of preexposure. Schmajuk, Lam, and Gray (1996) suggested that, under some circumstances, preexposure effects might be nonmonotonic, that is, impairing subsequent learning with some amounts of stimulus preexposure and facilitating it with other amounts. In our 
unpublished experiment, we examined the effects of 64 or 128 preexposures of an auditory cue on the subsequent learning, using the within-subjects design of Experiment $2 \mathrm{~b}$ (which included 80 preexposures). It is conceivable that fewer or more preexposure presentations of the auditory cue might give rise to the facilitation effect observed in Experiment 1 even under the testing conditions of Experiment 2b. However, the results of that unpublished experiment, combined with those of Experiment $2 b$, indicated a typical monotonic function relating amounts of latent inhibition to the amount of stimulus preexposure: latent inhibition effects with the food-cup measures were largest with 128 preexposures, intermediate with 80 preexposures, and minimal with 64 preexposures, with no evidence for facilitation at any number. By contrast, the amount of latent inhibition observed with the activity measure did not vary systematically with the number of cue preexposure presentations.

\section{Experiment 3}

The results of Experiments 1 and 2 indicated that in our within-subjects preexposure task, latent inhibition was obtained when the cues used in the training test were of the same modality (auditory or visual), but the identical preexposure conditions yielded facilitation effects when the training test cues came from different modalities. Thus, whatever is learned in the preexposure phase might have very different effects depending on the nature of the test. For example, construction of a more detailed and more consistent representation of the stimulus might enhance subsequent learning about it under some circumstances, but slow learning under others. Alternately, losses in CS salience from latent inhibition in the preexposure phase might be accompanied by habituation of unconditioned ORs to the CS, which could enhance the display of food-related CRs in the training test by releasing it from interference by those ORs in a training task-dependent manner. For example, given that habituation of ORs is more likely to generalize across cues within the same modality than across cues of different modalities, a comparison of the learning rates of two same-modality CSs might be less affected by differential interference by ORs than comparisons between CSs of different modalities.

Another intuition about how the two training test conditions might influence the display of latent inhibition considers context change between preexposure and the training test. One approach to understanding latent inhibition is that animals build up "no-event" outcome expectancies in the preexposure phase, which interfere with establishing new "sucrose" expectancies in the training test (Bouton, 1993). If these expectancies are context specific, then changes in context may release the animal from interference, reducing the impact of latent inhibition and potentially allowing other countervailing tendencies, such as familiarity or habituation of ORs, to dominate in the training test. Notably, latent inhibition effects rarely survive explicit context changes between preexposure and training test phases in intact animals.

Our intuition was that in our within-subjects preexposure task, the change in context from a single event in preexposure to two events in the training test disrupts latent inhibition, and that the addition of a same-modality stimulus would be less disruptive than the addition of a stimulus from a new modality. In Experiment 3, we examined some implications of this possibility, using both the two-modality training test procedure used in Experiment 1 and a standard one-stimulus preexposure and training test procedure. Rats first received preexposure to either one cue (a noise), two cues (a noise and a light), or the chamber alone. Then, half of the rats in each of these groups received a training test with both the light and noise CSs, as in Experiment 1. If context change disrupts latent inhibition, then we would expect reduced latent inhibition or even facilitation in the training test after exposure to the noise alone (as in Experiment 1), but latent inhibition after exposure to both cues to be used in the training test. The other half of the rats in each preexposure group received a training test that included only the noise CS. In this case, there would be minimal context change from the preexposure phase in rats that received noise-alone preexposure, and they might show latent inhibition, rather than the facilitation we predicted to occur after noise-alone preexposure and a training test with both noise and light. Furthermore, rats that received preexposure to both noise and light would experience greater context change when shifted to a noise-alone training, and thus might be expected to show less latent inhibition, or even facilitation in the training test. Thus, when the training test included both noise and light conditioning trials, we expected more latent inhibition after the noise and light preexposure treatment than after the noise-alone preexposure treatment, but when only the noise was presented in the training test, we anticipated greater latent inhibition in the noise-alone preexposure condition.

\section{Method}

The subjects were 50 Sprague-Dawley rats (25 female), maintained as in the previous experiments. Preexposure and training occurred in the same apparatus as was used in Experiments 1 and 2. Table 1 shows an outline of the procedures of Experiment 3. Rats first received eight 64-min preexposure sessions. In each of these sessions, rats were placed in the experimental chambers and given 16 nonreinforced presentations each of a 10 -s white noise (78 $\mathrm{dB})$ and a 10-s panel light (Groups NP/NP+ and NP/N+) randomly intermixed, or nonreinforced presentations of only that noise ( 16 per session in half of those rats and 32 per session in the others; Groups N/NP+ and N/N+), or no explicit events (Groups box/ $\mathrm{NP}+$ and box $/ \mathrm{N}+$ ). Then, all rats received food cup training 
as in the previous experiments, followed by five 64-min training test sessions that included either four reinforced-noise and four panel-light presentations, randomly intermixed (Groups NP/ $\mathrm{NP}+, \mathrm{N} / \mathrm{NP}+$, and box/NP+), or four reinforced noise presentations (Group NP/N+, N/N+, and box/N+). There were two replications, one with 24 rats and one with 26 rats, each conducted at Johns Hopkins University.

\section{Results}

Tables 2 shows activity counts on the final session of preexposure. Baseline (pre-CS) activity counts were affected by the type of preexposure treatment: rats that received both panel light and noise presentations showed higher baseline activity levels in the early preexposure sessions. Surprisingly, there were no systematic differences among the groups in responding during the preexposed CSs themselves. ANOVA of activity prior to noise cue presentations showed a significant main effect of sessions, $F(7,196)=9.411, p<.001$, $\eta^{2}=.252$, and a significant Preexposure Condition (NP vs. N) $\times$ Sessions interaction, $F(7,196)=9.89, p<.001, \eta^{2}=.261$. ANOVA of these counts confined to the first four sessions also revealed a significant main effect of preexposure, $F(1,28)=$ $14.91, p<.001, \eta^{2}=.347$, with greater responding in the NP condition. Although ANOVAs of responding during the first and last halves of the CS interval also showed a significant sessions effect and a significant Preexposure $\times$ Sessions interaction ( $\left.p \mathrm{~s}<.003, \eta^{2} \mathrm{~s}>.103\right)$, we saw no systematic differences. ANOVAs of responding on panel light trials (Groups $\mathrm{NP} / \mathrm{NP}+$ and NP/N+ only) showed significant effects of sessions in all three sampling intervals, $F_{\mathrm{s}}(7,98)>21.20, p \mathrm{~s}<$ $.001, \eta^{2} \mathrm{~s}>.602$.

Figures 5, 6, and 7 show responding during the training test phase of Experiment 3. The primary finding was that in the case of the food-cup measures, the relative effectiveness of the noise-alone $(\mathrm{N})$ and noise and panel light (NP) preexposure treatments depended on whether they were assessed by training only the noise $(\mathrm{N}+)$, or by training both the noise and the panel light (NP+). When tested with sessions that included both noise and panel light trials (as in Experiment 1), the noise and panel light preexposure procedure produced more latent inhibition than the noise alone preexposure procedure. Indeed, with the time in food-cup measure under these test conditions, prior exposure of the noise alone facilitated conditioning to the noise (as in Experiment 1), whereas preexposure to both stimuli produced latent inhibition of conditioning to both noise and light. By contrast, if only noise-sucrose trials were presented in the test phase, preexposure of only the noise produced substantially more latent inhibition than preexposure of both cues, although both preexposure treatments produced significant latent inhibition effects.

Figure 5 shows the time in food-cup measure. Figure $5 \mathrm{c}$ and f show responding during the last half of the noise CS intervals
Table 1. Outline of procedures

\begin{tabular}{|c|c|c|}
\hline & Preexposure & Training test \\
\hline \multicolumn{3}{|l|}{ Experiment 1} \\
\hline Group A & (80) a1- & a $1 \rightarrow$ suc, $v 1 \rightarrow$ suc \\
\hline Group V & (80) v1- & a1 $\rightarrow$ suc, $v 1 \rightarrow$ suc \\
\hline \multicolumn{3}{|l|}{ Experiment 2a } \\
\hline & (80) v1- & $\mathrm{v} 1 \rightarrow \mathrm{suc}, \mathrm{v} 2 \rightarrow \mathrm{suc}$ \\
\hline \multicolumn{3}{|l|}{ Experiment $2 b$} \\
\hline & (80) a1- & $\mathrm{a} 1 \rightarrow \mathrm{suc}, \mathrm{a} 2 \rightarrow \mathrm{suc}$ \\
\hline \multicolumn{3}{|l|}{ Experiment 3} \\
\hline \multicolumn{3}{|l|}{ Group } \\
\hline $\mathrm{NP} / \mathrm{NP}+$ & $\mathrm{n}-, \mathrm{p}-$ & $\mathrm{n} \rightarrow \mathrm{suc}, \mathrm{p} \rightarrow$ suc \\
\hline N/NP+ & $n-$ & $\mathrm{n} \rightarrow \mathrm{suc}, \mathrm{p} \rightarrow$ suc \\
\hline box/NP+ & -- & $\mathrm{n} \rightarrow$ suc, $\mathrm{p} \rightarrow$ suc \\
\hline $\mathrm{NP} / \mathrm{N}+$ & $\mathrm{n}-, \mathrm{p}-$ & $\mathrm{n} \rightarrow \mathrm{suc}$ \\
\hline $\mathrm{N} / \mathrm{N}+$ & n- & $\mathrm{n} \rightarrow \mathrm{suc}$ \\
\hline box/N+ & -- & $\mathrm{n} \rightarrow \mathrm{suc}$ \\
\hline \multicolumn{3}{|l|}{ Experiment 4} \\
\hline \multicolumn{3}{|l|}{ Group } \\
\hline $\mathrm{S} / \mathrm{N}$ & $\mathrm{n}-$ & $\mathrm{n} \rightarrow \mathrm{suc}$ \\
\hline S/box & -- & $\mathrm{n} \rightarrow \mathrm{suc}$ \\
\hline $\mathrm{W} / \mathrm{N}$ & $n-$ & $\mathrm{n} \rightarrow \mathrm{suc}$ \\
\hline W/box & -- & $\mathrm{n} \rightarrow \mathrm{suc}$ \\
\hline
\end{tabular}

Note . suc $=$ sucrose reinforcement, " -" = nonreinforced presentations, “-_" $=$ exposure to chamber only, $\mathrm{n}=$ white noise, $\mathrm{p}=$ panel light. In Experiment 1, a1 and v1 refer to a $1500-\mathrm{Hz}$ tone and a panel light stimulus. In Experiment 2, a1 and a2 refer to $1500-\mathrm{Hz}$ and $400-\mathrm{Hz}$ tones, counterbalanced, and v1 and v2 refer to panel and house lights, counterbalanced

as in original ms. The ANOVA for this measure showed all main effects and interactions to be significant $\left(p s<.044, \eta^{2} \mathrm{~s}\right.$ $>.084)$, except for the main effect of training $(p=.696)$. However, the critical outcome was the significant Preexposure (NP, N, or box) $\times$ Training $(\mathrm{NP}+$ or $\mathrm{N}+), F(2$, 44) $=20.73, p<.001, \eta^{2}=.485$, and Preexposure $\times$ Training $\times$ Sessions, $F(8,176)=3.29, p=.002, \eta^{2}=.130$, interactions.

Table 2 Mean $( \pm S E M)$ activity counts in the last preexposure session of Experiment 3

\begin{tabular}{llll}
\hline CS: Group & pre-CS & CS: first half & CS: second half \\
\hline Noise: NP-NP & $50.1 \pm 8.8$ & $80.8 \pm 10.7$ & $70.4 \pm 12.0$ \\
Noise: N-NP & $58.5 \pm 9.4$ & $68.3 \pm 5.3$ & $68.1 \pm 9.9$ \\
Noise: NP-N & $50.2 \pm 9.0$ & $71.9 \pm 13.0$ & $76.3 \pm 11.7$ \\
Noise: N-N & $49.9 \pm 8.9$ & $106.1 \pm 10.5$ & $98.8 \pm 10.8$ \\
Light: NP-NP & $48.3 \pm 8.4$ & $62.5 \pm 9.8$ & $63.8 \pm 10.6$ \\
Light: NP-N & $55.9 \pm 12.0$ & $62.9 \pm 10.5$ & $70.2 \pm 10.7$ \\
\hline
\end{tabular}

Note. $\mathrm{CS}=$ conditioned stimulus 

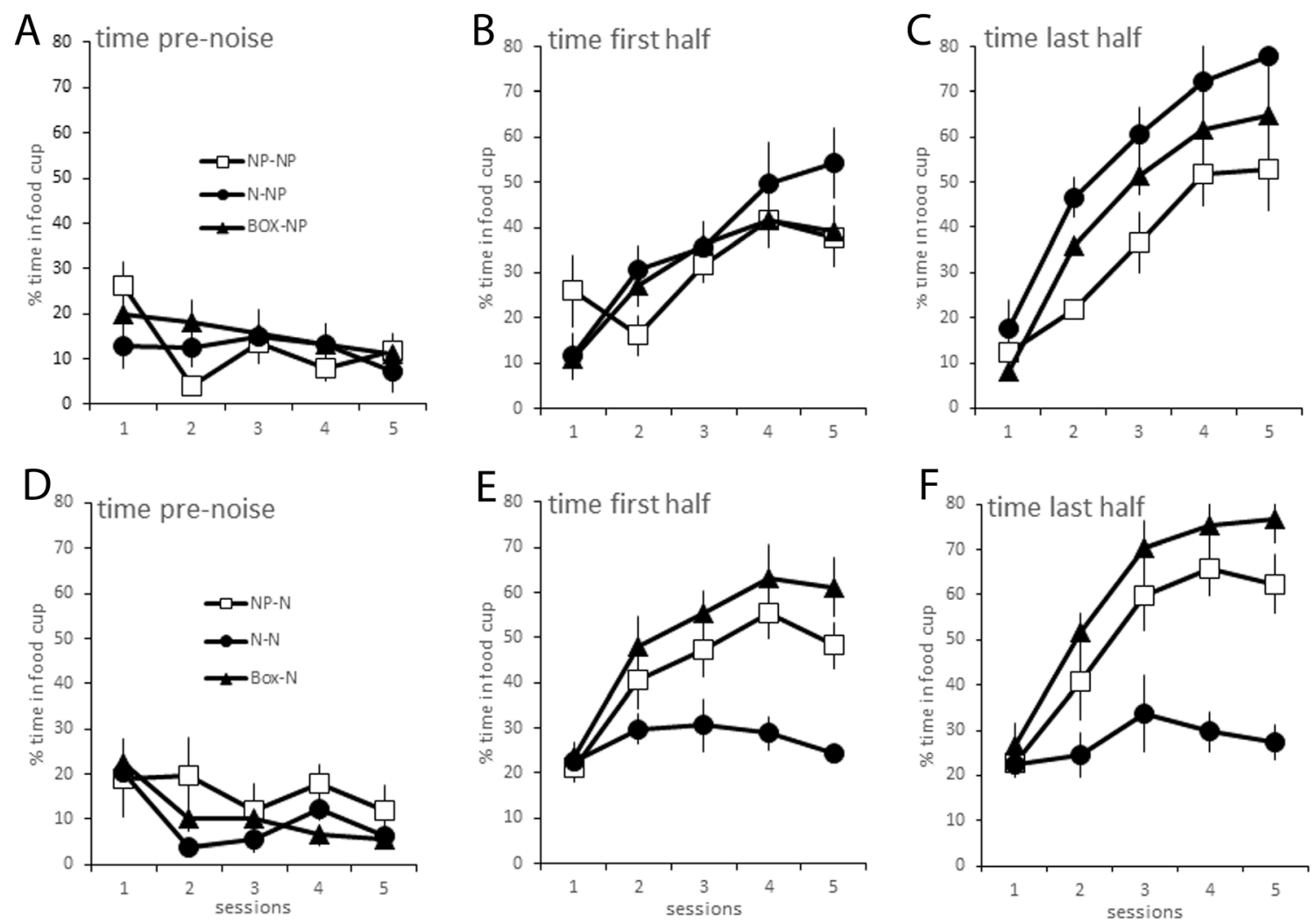

Fig. 5 Mean $( \pm S E M)$ time in the food cup during the training test phase of Experiment 3. In the preexposure phase, Groups NP-NP and NP-N received nonreinforced presentations of both the noise and the panel light, Groups N-NP and N-N received nonreinforced presentations of only the noise, and Groups Box-NP and Box-N were placed in the chambers but did not receive any explicit events. Panels a-c show responding in rats that received separate reinforced presentations of both the noise and panel

We partitioned the Preexposure $\times$ Training interaction with a series of planned comparisons. The first assessed the primary hypothesis of this study, that more latent inhibition would be observed when preexposure and test conditions matched than when they differed. This contrast, between responding in the $\mathrm{NP}$ and $\mathrm{N}$ preexposed rats, depending on whether their training test used the $\mathrm{NP}+$ or $\mathrm{N}+$ procedure, was significant $(p<.001)$. Each of the components of that contrast was also significant: The contrast of NP and N preexposure conditions was significant $(p s<.001)$ in both the rats tested with NP+ (in which NP preexposure produced more latent inhibition than $\mathrm{N}$ preexposure) and those tested with $\mathrm{N}+$ procedures (in which $\mathrm{N}$ preexposure produced more latent inhibition than NP preexposure). Furthermore, among rats tested with both the noise and panel light, preexposure to the noise alone significantly facilitated $(p=.048)$ responding relative to those simply placed in the chamber, whereas preexposure to both cues produced only a marginally significant $(p=.081)$ latent inhibition effect, compared to chamber-alone rats.

Only portions of this pattern were observed in the first half of the noise CS (Fig. 5b and e). As with responding in the last half of the noise CS interval, both the Preexposure $\times$ Training, light stimuli in the training test, and panels $\mathrm{d}-\mathrm{f}$ show responding in the rats that received reinforced presentations of only the noise in the training test. Panels a and d show responding in the $5 \mathrm{~s}$ prior to stimulus presentations, panels $\mathrm{b}$ and e show responding during the first $5 \mathrm{~s}$ of each stimulus, and panels $\mathrm{c}$ and $\mathrm{f}$ show responding during the last $5 \mathrm{~s}$ of each stimulus

$F(2,44)=6.54, p=.003, \eta^{2}=.229$, and Preexposure $\times$ Training $\times$ Sessions, $F(8,176)=4.29, p<.001, \eta^{2}=.163$, interactions were significant. However, the pattern of differences differed from that observed in last-half responding. Although the primary contrast, between responding in the $\mathrm{NP}$ and N preexposed rats, depending on whether they were tested with the $\mathrm{NP}+$ or $\mathrm{N}+$ procedures, was significant $(p=$ .014 ), the contrast of NP and N preexposure conditions was significant only for rats tested in the $\mathrm{N}+$ condition $(p=.012)$; this contrast was not significant for rats tested in the NP+ condition ( $p=.336$ ). Furthermore, in comparison to responding of rats preexposed only to the experimental chamber, only rats in the $\mathrm{N} / \mathrm{N}+$ group showed significant latent inhibition $(p<.001$, other $p$ s $>.200)$. Finally, during the pre-CS periods (Fig. 5a and d), there were no differences among groups; only the effect of sessions was significant, $F(4,176)=6.44, p<.001, \eta^{2}=.128$; other $p \mathrm{~s}>.350$.

Figure 6 shows the food-cup entry rate measure. Figure $6 \mathrm{c}$ and $\mathrm{f}$ show responding during the last half of the noise CS intervals. Except for the main effect of training $(p=.803)$ and the Training $\times$ Sessions interaction $(p=$ .300 ), all main effects and interactions in this ANOVA 

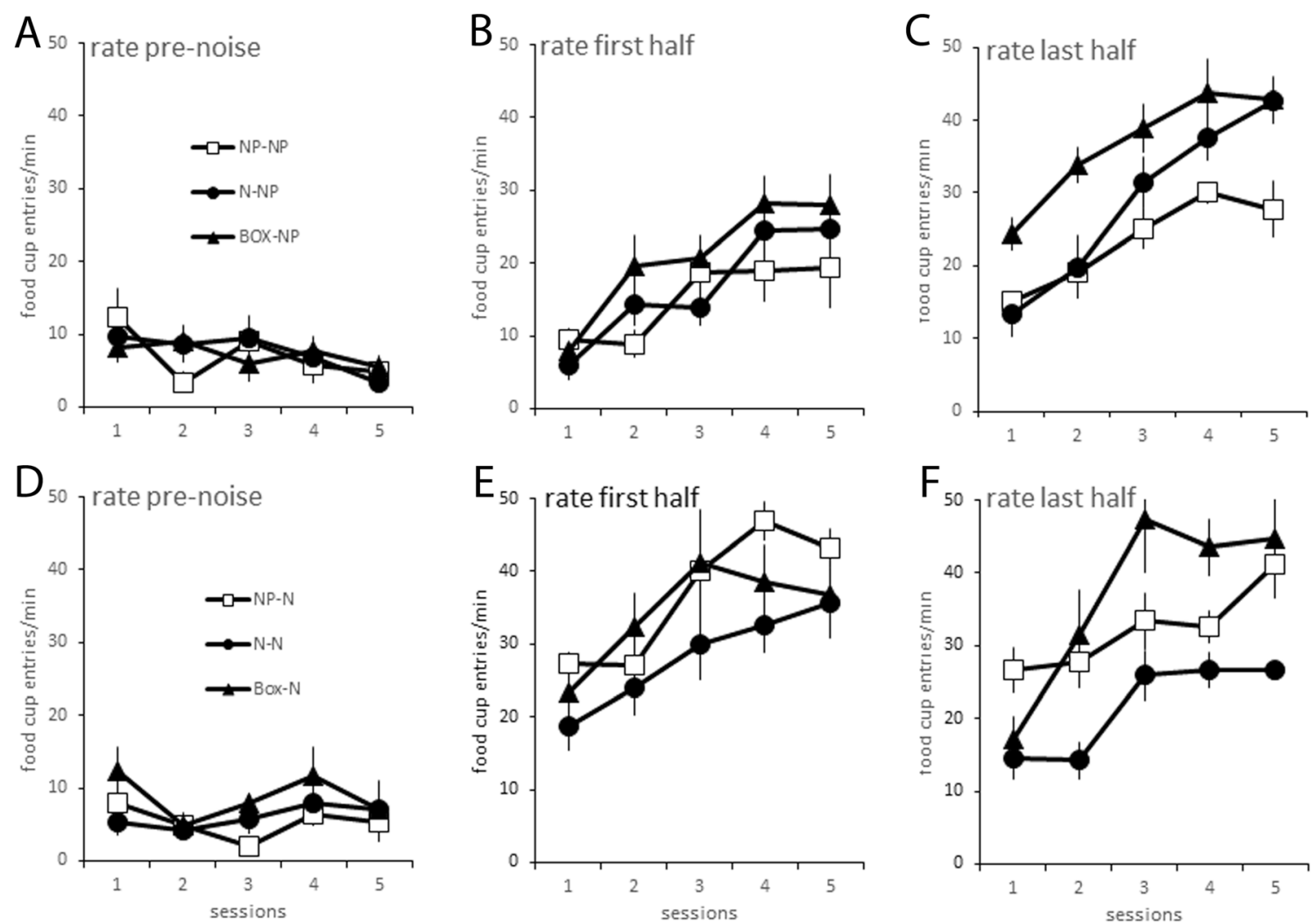

Fig. 6 Mean $( \pm S E M)$ food cup entries/min during the training test phase of Experiment 3. In the preexposure phase, Groups NP-NP and NP-N received nonreinforced presentations of both the noise and the panel light, Groups N-NP and N-N received nonreinforced presentations of only the noise, and Groups Box-NP and Box-N were placed in the chambers but did not receive any explicit events. Panels a-c show responding in rats that received separate reinforced presentations of both the noise and panel

light stimuli in the training test, and panels $\mathrm{d}-\mathrm{f}$ show responding in the rats that received reinforced presentations of only the noise in the training test. Panels a and $\mathrm{d}$ show responding in the $5 \mathrm{~s}$ prior to stimulus presentations, panels $\mathrm{b}$ and e show responding during the first $5 \mathrm{~s}$ of each stimulus, and panels $\mathrm{c}$ and $\mathrm{f}$ show responding during the last $5 \mathrm{~s}$ of each stimulus

were significant $\left(p s<.019, \eta^{2} \mathrm{~s}>.166\right)$. However, the critical outcome was again the significant Preexposure $(\mathrm{NP}, \mathrm{N}$, or box $) \times$ Training $(\mathrm{NP}+$ or $\mathrm{N}+), F(2,44)=$ $4.39, p=.018, \eta^{2}=.166$, and Preexposure $\times$ Training $\times$ Sessions, $F(8,176)=2.56, p=.011, \eta^{2}=.104$, interactions. As with the food cup time measure, we partitioned the Preexposure $\times$ Training interaction with a series of planned comparisons. The first assessed the primary hypothesis of this study, that more latent inhibition would be observed when preexposure and test conditions matched than when they differed. This contrast, between responding in the NP and $\mathrm{N}$ preexposed rats, depending on whether they were tested with the NP+ or N+ procedures, was significant $(p=.005)$. However, the contrast of $\mathrm{NP}$ and $\mathrm{N}$ preexposure conditions was significant only in the rats tested with $\mathrm{N}+$, in which $\mathrm{N}$ preexposure produced more latent inhibition than NP preexposure $(p=.008)$; although in the rats tested with NP+ there was a trend toward more latent inhibition after NP preexposure, that difference was insignificant $(p=.160)$. There was no evidence for facilitation with this measure; indeed, compared to performance in the box-preexposed rats,

significant latent inhibition was observed in Groups NP/ $\mathrm{NP}+(p<.001), \mathrm{N} / \mathrm{NP}+(p=.040)$, and $\mathrm{N} / \mathrm{N}+(p<.001)$, but not Group NP/N+ $(p=.253)$.

This predicted pattern was not observed in the first half of the noise CS (Fig. 6b and e). Neither the Preexposure $x$ Training $(p=.210)$ nor the Preexposure $\times$ Training $\times$ Sessions $(p=.335)$ interaction was significant. The only significant effects were those of training test condition (rats tested with both cues showed higher rate of food-cup entry), $F(1,44)$ $=41.58, p<.001, \eta^{2}=.486$, and sessions, $F(4,176)=40.88, p$ $<.001, \eta^{2}=.481$, although, consistent with the effects noted with the time in the food cup measure, among rats tested with only reinforced noise trials, there was less responding (more latent inhibition, $p=.048$ ) after preexposure to the noise alone than after preexposure to both light and noise. Finally, pre-CS food cup entry rates (Fig. 6a and d) did not differ across groups; only the effect of sessions was significant, $F(4,176)$ $=3.24, p=.014, \eta^{2}=.069$, other $p \mathrm{~s}>.104$.

Figure 7 shows activity responding on noise CS trials. This measure showed equivalent latent inhibition after both preexposure treatments, in both noise-alone and noise and panel light testing procedures. Figure $7 \mathrm{~b}$ and e show activity 

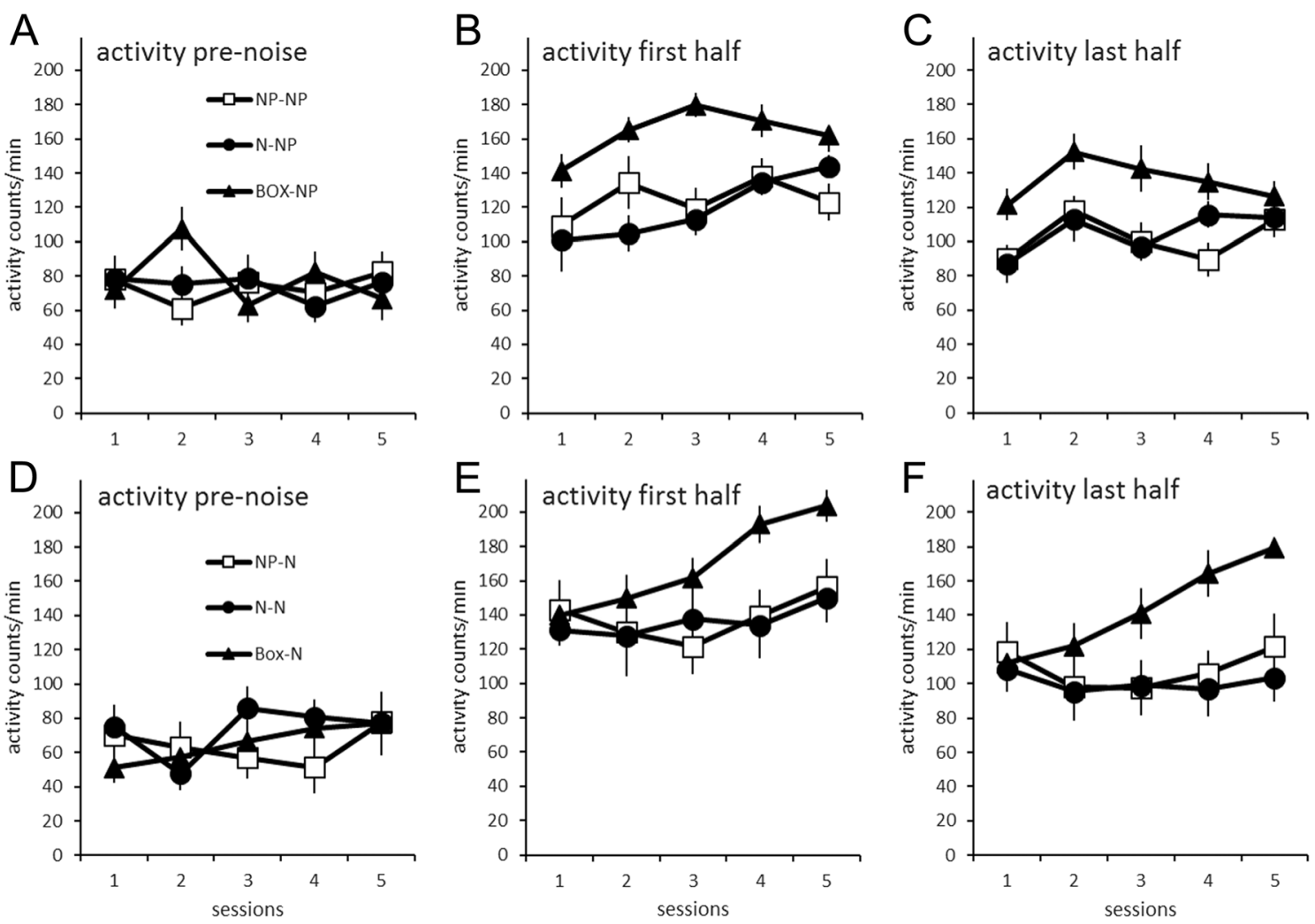

Fig. 7 Mean $( \pm S E M)$ activity counts/min during the training test phase of Experiment 3. In the preexposure phase, Groups NP-NP and NP-N received nonreinforced presentations of both the noise and the panel light, Groups N-NP and N-N received nonreinforced presentations of only the noise, and Groups Box-NP and Box-N were placed in the chambers but did not receive any explicit events. Panels a-c show responding in rats that received separate reinforced presentations of both the noise and panel

light stimuli in the training test, and panels $\mathrm{d}-\mathrm{f}$ show responding in the rats that received reinforced presentations of only the noise in the training test. Panels a and d show responding in the $5 \mathrm{~s}$ prior to stimulus presentations, panels $\mathrm{b}$ and e show responding during the first $5 \mathrm{~s}$ of each stimulus, and panels $\mathrm{c}$ and $\mathrm{f}$ show responding during the last $5 \mathrm{~s}$ of each stimulus

during the first half of the noise CS intervals. ANOVA showed significant main effects of preexposure, $F(2,44)=11.25, p<$ $.001, \eta^{2}=.338$, and sessions, $F(4,176)=3.30, p=.012, \eta^{2}=$ .070 , and significant Training $\times$ Sessions, $F(4,176)=3.91, p$ $=.005, \eta^{2}=.082$, and Preexposure $\times$ Training $\times$ Sessions, $F(8$, 176) $=2.50, p=.013, \eta^{2}=.102$, interactions. Individual contrasts showed that, compared to rats preexposed only to the chambers, significant latent inhibition was observed in all four preexposed groups $(p s<.029)$.

Figure $7 \mathrm{c}$ and $\mathrm{f}$ show activity during the last half of the noise CS intervals. ANOVA showed significant main effects of preexposure, $F(2,44)=9.77, p<.001, \eta^{2}=.307$, and sessions, $F(4,176)=8.65, p<.001, \eta^{2}=.164$, and a significant Preexposure $\times$ Training $\times$ Sessions interaction, $F(8,176)$ $=2.05, p=.043, \eta^{2}=.085$. As with first-half activity, compared to chamber-only preexposure, both preexposure treatments produced significant latent inhibition under both test procedures $(p \mathrm{~s}<.050)$. Finally, Fig. $7 \mathrm{a}$ and d show baseline activity in the intervals before noise trials. ANOVA showed no significant effects or interactions ( $p s>.169)$.

Figure 8 shows the acquisition of conditioning to the panel light $\mathrm{CS}$ in the NP+ groups (the only groups in which conditioning of the panel light was conducted). Prior exposure to that stimulus produced latent inhibition in testing, compared to either exposure to the chamber alone or exposure to the noise stimulus. ANOVAs of time in food-cup responding in both the first (Fig. 8b) and last (Fig. 8c) halves of the CS interval showed significant effects of preexposure, $F_{\mathbf{S}}(2,23)>$ $4.66, p \mathrm{~s}<.020, \eta^{2} \mathrm{~s}>.288$, and sessions, $F_{\mathrm{s}}(4,92)>19.74, p \mathrm{~s}$ $<.001, \eta^{2} \mathrm{~s}>.461$; other $p \mathrm{~s}>.194$. Individual contrasts showed that responding during the last half of the panel light was significantly lower in Group NP/NP+ $(p s<.021)$ than in either Groups N/NP+ or box/NP+, which did not differ $(p=$ .160 ), and responding during the first half was significantly lower in Group NP/NP+ than responding in Group box/NP+ ( $p=.006$ ). Responding prior to panel light presentations (Fig. 8a) did not differ among the groups; ANOVA showed no significant effects or interactions ( $p$ s $>.097$ ).

Latent inhibition to the panel light CS appeared somewhat weaker in the food-cup entry measure (Fig. 8d-f). ANOVA of responding in the last half of the panel light interval (Fig. 8f) showed a marginally significant effect of preexposure, $F(2$, 23) $=3.15, p=.062, \eta^{2}=.215$, and a significant effect of sessions, $F(4,92)=42.30, p<.001, \eta^{2}=.648$; other $p \mathrm{~s}>.102$. 

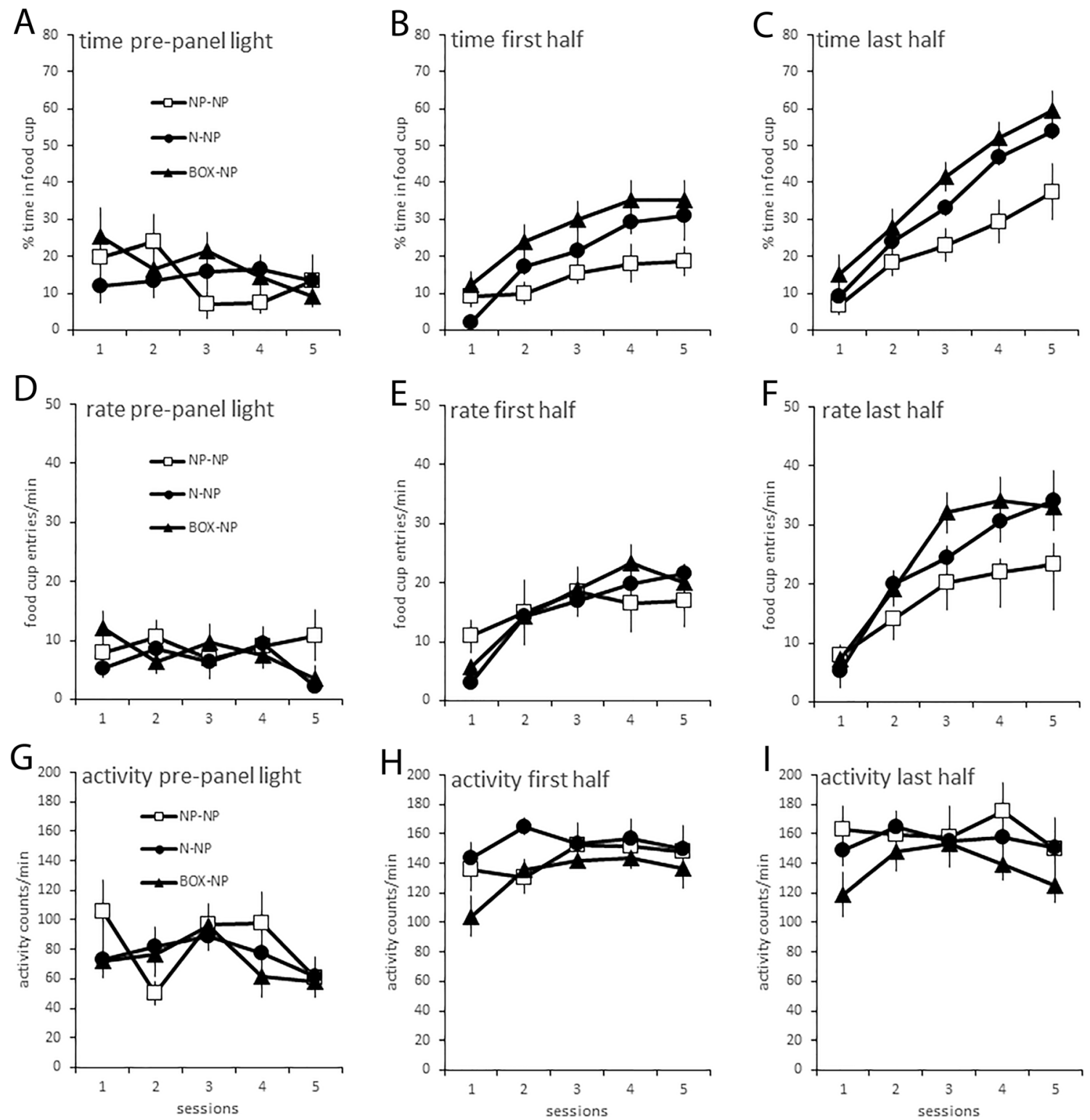

Fig. 8 Mean $( \pm S E M)$ responding to the panel light stimulus in rats that received separate reinforced presentations of both the noise and panel light stimuli in the training test in Experiment 3. In the preexposure phase, Group NP-NP received nonreinforced presentations of both the noise and the panel light, Group N-NP received nonreinforced presentations of only the noise, and Group Box-NP was placed in the chambers during the preexposure phase but did not receive any explicit events. Panels a-c show percentage time in the food cup, panels $\mathrm{d}-\mathrm{f}$ show food cup entry rates, and panels $\mathrm{g}-\mathrm{i}$ show activity counts. Panels a, $\mathrm{d}$, and $\mathrm{g}$ show responding in the $5 \mathrm{~s}$ prior to stimulus presentations, panels $\mathrm{b}, \mathrm{e}$, and $\mathrm{h}$ show responding during the first $5 \mathrm{~s}$ of each stimulus, and panels $\mathrm{c}$, $\mathrm{f}$, and i show responding during the last $5 \mathrm{~s}$ of each stimulus
Individual contrasts showed that responding was significantly lower in Group NP/NP+ than in Group box/NP+ $(p=.021$; other $p \mathrm{~s}>.111)$. ANOVA of responding during the first half (Fig. 8e) showed only a significant effect of sessions, $F(4,92)$ $=21.73, p<.001, \eta^{2}=.486$; other $p$ s $>.080$. Food-cup entries prior to panel light presentations (Fig. 8d) did not differ across groups; ANOVA showed no significant effects or interactions (ps > .115).

Surprisingly, activity during the panel light CS (Fig. 8g-i) revealed little evidence for latent inhibition or even conditioning (that is, there was no evidence of an acquisition function; but see Rescorla, 1988). The only significant effect or interaction was of sessions, for activity in the pre-CS interval, $F(4$, $92)=3.38, p=.013, \eta^{2}=.128$, and in the first half of the CS interval, $F(4,92)=3.33, p=.014, \eta^{2}=.126$; other $p s>.167$.

\section{Discussion}

The relative effectiveness of the one (N) and two (NP) stimulus preexposure procedures depended on the nature of the training test: More latent inhibition was observed if the preexposure and training test conditions matched than if they 
did not. Preexposure effects additionally varied depending on the choice of response measure. With the food-cup time measure, if both the auditory and visual CSs were reinforced in the training test $(\mathrm{NP}+)$, the $\mathrm{N}$ preexposure procedure produced facilitation (as in Experiment 1), whereas the NP preexposure procedure produced latent inhibition. By contrast, if only the noise was reinforced in the training test $(\mathrm{N}+)$, the $\mathrm{N}$ preexposure procedure produced profound latent inhibition, whereas the NP procedure had no significant effect. With the food-cup entry-rate measure, more latent inhibition was observed if the preexposure and training test conditions matched than if they did not, but both preexposure procedures produced latent inhibition under both training test conditions. Finally, with the activity measure, both preexposure treatments slowed subsequent learning equivalently, regardless of training test procedure. Interestingly, although rats tested with both noise and light trials showed patterns of activity as in the previous experiments, with lower levels of activity to the preexposed cue from the beginning of the test phase, in rats tested with the noise alone, latent inhibition emerged over trials, as with the other measures. We discuss implications of this observation in the General Discussion.

\section{Experiment 4}

When a single stimulus was preexposed, but both that CS and a CS of another modality were trained in the test phase (Experiments 1 and 3), we observed preexposure facilitation effects. One inference from this observation is that facilitation effects may depend on the two-modality, two-stimulus test procedure. In Experiment 4, we sought a facilitation effect with a simple, one-stimulus design, in which the only contextual change between preexposure and test was the addition of reinforcement. If latent inhibition effects depend on minimal contextual change when reinforcement is introduced in the test phase, then manipulations that make that change more obvious should discourage latent inhibition and encourage the display of facilitation. We reasoned that the addition of reinforcement would provide a more distinctive change the weaker the salience of the context. In Experiment 4, we manipulated the salience of the experimental context by altering the intensity of the background sound level. Some rats received their preexposure treatment and training tests in chambers with the background sound intensity used in Experiments 1-3, and others received preexposure and training in chambers with a weaker background sound level. We hypothesized that with the "weak" context, preexposure should produce weaker latent inhibition, or perhaps facilitation, as in Experiments 1 and 3, even with a simple one-stimulus, between-subjects design. On the other hand, if facilitation were some artifact of training two cues in testing, it would not be expected in this experiment.

\section{Method}

The subjects were 28 (14 female) Sprague-Dawley rats (Charles River, Raleigh, NC). The same apparatus was used as in the previous experiments. Throughout the experiment, for rats in the "strong" context condition, 72-dB background noise was provided by ventilating fans mounted on the external shell that enclosed the experimental chambers. For rats in the "weak" context condition, those fans were silent, providing a background intensity of $58 \mathrm{~dB}$. In both conditions, the experimental chambers were always dark. The experiment was conducted at Duke University.

Table 1 shows an outline of the procedures of Experiment 4. Half of the rats in each context condition first received eight 64min preexposure sessions, each of which included 32 presentations of a 10-s 79-dB white-noise cue, with random ITIs. The other half of the rats in each context condition were simply placed in the chambers during those sessions, with no explicit events. Then, all rats received a single session of food-cup training with the sucrose reinforcer, as in the previous experiments. Finally, all rats received eight reinforced presentations of the noise CS in each of five 64-min training sessions.

\section{Results}

Rats rapidly habituated activity responding to the noise CS over the course of the preexposure phase, regardless of context intensity. ANOVAs of activity during pre-CS, and first and second halves of CS periods all showed significant effects of sessions, $F_{\mathrm{S}}(7,84)>2.73, p \mathrm{~s}<.014, \eta^{2}>.185$, other $p \mathrm{~s}>$ .283. On the final preexposure session, mean \pm SEM activity counts/min were $81.8 \pm 14.2,92.2 \pm 17.1$, and $94.3 \pm 19.3$ in the pre-CS, first half of CS, and last half of CS intervals, respectively, in the strong context, and 80.4 $\pm 12.9,83.6 \pm$ 13.7 , and $96.0 \pm 8.6$ in those intervals in the weak context.

Although in the strong context (that used in the previous experiments) preexposure of the noise resulted in latent inhibition when the noise was paired with food, regardless of response measure, the pattern of results observed in the weak context depended on the response measure. Facilitation was observed with the time in food-cup measure, latent inhibition was observed with the activity measure, and no significant effect was observed with the food cup entry rate measure.

Figure $9 \mathrm{a}-\mathrm{c}$ show the time in food-cup measure in the training test of Experiment 4. ANOVA of responding during the last half of the CS (Fig. 9c) showed significant main effects of context, $F(1,23)=8.77, p=.007, \eta^{2}=.276$, and sessions, $F(4,92)=38,47, p<.001, \eta^{2}=.626$. Most important, the Context $\times$ Preexposure interaction was significant, $F(1,23)=$ $12.55, p=.002, \eta^{2}=.353$. Individual contrasts showed reliable latent inhibition in the strong context $(\mathrm{p}=.030)$, and significant facilitation in the weak context $(p=.012)$. In addition, although the salience of the context had no effect on test 

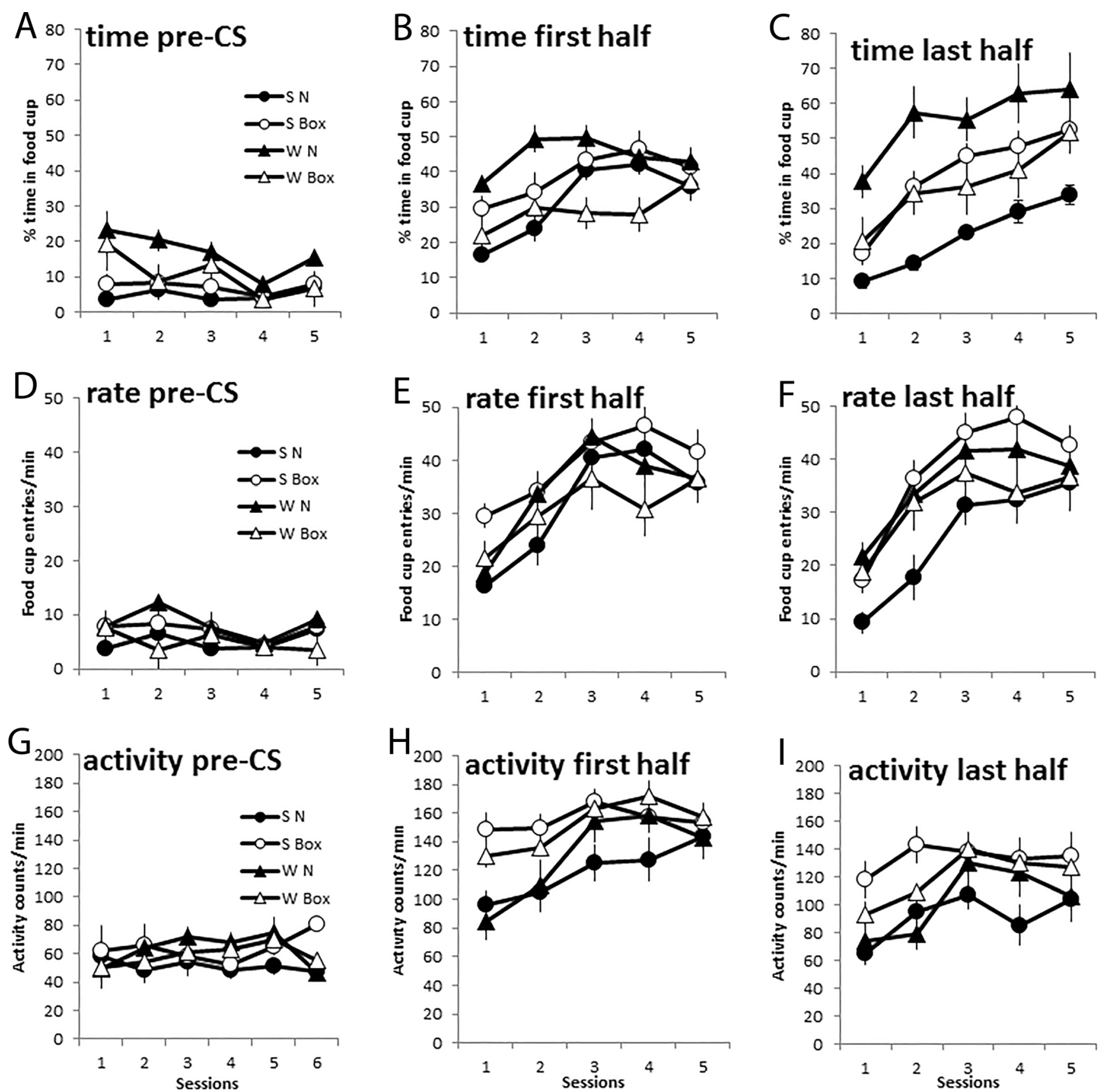

Fig. 9 Mean $( \pm S E M)$ responding to the noise in the training test of Experiment 4. Preexposure and testing occurred in either a more salient strong (S) context or a less salient weak (W) context. In the preexposure phase, rats received either nonreinforced presentations of the noise $(\mathrm{N})$ or no explicit stimulus (Box). Panels a-c show percentage time in the food

cup, panels $\mathrm{d}-\mathrm{f}$ show food cup entry rates, and panels $\mathrm{g}-\mathrm{i}$ show activity counts. Panels a, d, and g show responding in the $5 \mathrm{~s}$ prior to stimulus presentations, panels $\mathrm{b}, \mathrm{e}$, and $\mathrm{h}$ show responding during the first $5 \mathrm{~s}$ of each stimulus, and panels $\mathrm{c}, \mathrm{f}$, and i show responding during the last $5 \mathrm{~s}$ of each stimulus

learning in rats preexposed to the chambers alone $(p=.689)$, in rats preexposed to the noise, learning about the noise was significantly greater in the weak context than in the strong context $(p<.001)$. ANOVA of time in the food cup during the first half of the CS intervals (Fig. 9b) showed a main effect of sessions, $F(4,92)=10.42, p<.001, \eta^{2}=.312$, and significant Context $\times$ Sessions, $F(4,92)=3.82, p=.006, \eta^{2}=.142$, and Context $\times$ Preexposure interactions, $F(1,23)=8.95, p=$
$.006, \eta^{2}=.280$. Individual comparisons showed significant facilitation in the weak context ( $p=.006)$, but no significant difference in the strong context $(p=.209)$. As with last half responding, although the salience of the context had no effect on learning in rats preexposed to the chambers alone $(p=$ .082 ), in rats preexposed to the noise, learning about the noise was significantly greater in the weak context than in in the strong $(p=.006)$. Finally, time in the food cup in the pre-CS 
periods (Fig. 9a) showed significant effects of context, $F(1$, 23) $=18.33, p<.001, \eta^{2}=.443$, and sessions, $F(4,92)=2.54$, $p=.045, \eta^{2}=.099$, and a significant Context $\times$ Preexposure interaction, $F(1,23)=6.29, p=.020, \eta^{2}=.215$. Individual comparisons showed significantly greater pre-CS responding in both groups of rats trained in the weaker context than in those trained in the strong context $(p s<.010)$. Although at first glance this observation might seem surprising, one possible account for it is that the weaker background sound level made operation of the solenoid valve easier to hear, enhancing context conditioning during food cup training, prior to the CS training test.

Figure $9 \mathrm{~d}-\mathrm{f}$ show food-cup entry rates during the training test of Experiment 4. ANOVA of last half entry rates (Fig. 9f) showed a significant effect of sessions, $F(4,92)=29.75, p<$ $.001, \eta^{2}=.564$, and a significant Preexposure $\times$ Context interaction, $F(1,23)=6.12, p=.021, \eta^{2}=.210$. Individual contrasts showed a significant latent inhibition effect in rats trained in the strong context $(p=.017)$, but no effect in the weak context $(p=.407)$. During the first half of the CS interval (Fig. 9e), ANOVA showed only an effect of sessions, $F(4,92)$ $=22.46, p<.001, \eta^{2}=.494$. Finally, ANOVA of pre-CS food cup entry rates (Fig. 9d) showed a significant Preexposure $\times$ Context interaction, $F(1,23)=4.92, p=.037, \eta^{2}=.176$, which did not appear to reflect any systematic differences.

Figure $9 \mathrm{~g}-\mathrm{i}$ show activity counts during the training test of Experiment 4. ANOVA of first half activity (Fig. 9h) showed significant effects of preexposure, $F(1,23)=9.40, p=.005, \eta^{2}$ $=.290$, and sessions, $F(4,92)=23.07, p<.001, \eta^{2}=.501$, and significant Preexposure $\times$ Sessions, $F(4,92)=3.64, p=.008$, $\eta^{2}=.137$, and Context $\times$ Sessions, $F(4,92)=3.70, p=.008$, $\eta^{2}=.139$, interactions, but no Context $\times$ Preexposure interaction $\left(F<1, p=.457, \eta^{2}=.024\right)$. Individual comparisons showed a significant latent inhibition effect $(p=.017)$ in the strong context and a marginally significant latent inhibition effect in the weak context $(p=.097)$. ANOVA of last half responding (Fig. 9i) also showed main effects of preexposure, $F(1,23)=7.82, p=.010, \eta^{2}=.254$, and sessions, $F(4,92)=$ $12.49, p<.001, \eta^{2}=.352$, and a significant Context $\times$ Session interaction, $F(4,92)=3.56, p=.010, \eta^{2}=.134$, but no Context $\times$ Preexposure interaction, $F(1,23)=1.35, p=$ $.257, \eta^{2}=.056$. Only the latent inhibition effect in the strong context was significant $(p=.014)$. Finally, ANOVA of baseline activity (Fig. 9g) showed no significant effects or interactions ( $p$ s > .184).

\section{Discussion}

When the noise CS was preexposed and trained in the strong context (that used in Experiments 1-3), all three measures of learning displayed latent inhibition. Thus, we replicated the results of the N/N+ and box $/ \mathrm{N}+$ conditions of Experiment 3. However, in the weak context, we found facilitation of learning about the preexposed cue with the food-cup time measure, latent inhibition with the activity measure, and no significant effect (but a trend toward facilitation) with the food-cup entry-rate measure. This facilitation is especially surprising given recent reports that latent inhibition may be enhanced with more salient CSs (Rodríguez, Alonso, \& Hall, 2015); reducing the background noise intensity in Experiment 4 might have been expected to increase the relative salience of the noise CS.

Within many theories of latent inhibition (to be considered in the General Discussion), latent inhibition should be maximal when the preexposure and test contexts are indistinguishable and minimized when they are readily distinguishable. When the chamber elements that bridged the two phases are of high salience, those strong constant cues may partially mask the only changed stimulus, that of cue outcome (nonreinforcement vs. reinforcement), encouraging the rats to integrate their experiences from those two phases, and hence display substantial latent inhibition. With less salient contextual cues, the outcome shift may be more important, allowing the rats to better distinguish reinforced from nonreinforced phases, and hence acquire associations with reinforcement more rapidly in the test phase, reducing the latent inhibition effect. Of course, such an approach alone does not predict net facilitation, without additional assumptions, such as release from competition from ORs or formation of a stronger representation of the preexposed cue.

Given such additional assumptions about the origins of facilitation, the results of Experiment 4 are also consistent with other theories of latent inhibition. For example, Wagner (1979) suggested that CSs lost their effectiveness as a result of the formation of context $\rightarrow$ CS associations, in the same way (within the Rescorla \& Wagner, 1972, model) as USs lose their effectiveness as they become predicted by CSs. That account anticipates the elimination of latent inhibition by context change, and is consistent with the results of Experiment 4, given the reasonable assumption that less salient contextual cues would former weaker associations with the explicit CS during the preexposure phase.

\section{General discussion}

Stimulus preexposure had different effects depending on the training test and the choice of response measure. In Experiments 1 and 3, preexposure to a visual or an auditory stimulus produced facilitation of acquisition of responding directed to the locus of US delivery (time in food cup) when both of those cues were (separately) paired with sucrose delivery in a training test. In Experiment 2, the same preexposure procedure resulted in slowed food-cup learning (latent inhibition) if the second stimulus in the training test was of the same modality as the preexposed stimulus. In Experiment 3, latent 
inhibition of food-cup learning was observed if both auditory and visual stimuli were presented in both preexposure and the training test. Finally, in Experiment 4, in which a single auditory stimulus was presented in both preexposure and the training test, latent inhibition of food-cup learning was observed if the auditory contextual cues were salient, but facilitation was obtained if they were nonsalient. By contrast, in all conditions, a general activity response appeared to show latent inhibition.

Three of these observations are especially notable. First, the amount of latent inhibition of learning produced by a given preexposure procedure depended on the training test procedure. In general, latent inhibition was more pronounced the more similar the preexposure and training test procedures. Second, although the typical outcome in studies of the effects of CS preexposure is slowed learning about the preexposed cue, in some cases we observed the opposite-facilitated learning about the preexposed cue. Third, conclusions about variables affecting the occurrence of latent inhibition or facilitation depended on the choice of response measure. After a brief summary of various classes of latent inhibition theories, we discuss each of these observations in turn, outlining their theoretical implications.

\section{Theories of latent inhibition}

Most theories of latent inhibition focus on the nature of the learning that occurs during the preexposure phase. A common notion is that presentation of a stimulus with no consequence results in "conditioned inattention" (Lubow \& Moore, 1959; Lubow, Schnur, \& Rifkin, 1976) to that cue, or some other loss in its associability, that is, its ability to participate in new associations, such as those examined in the training test phase. For example, Pearce and Hall (1980) suggested that a cue's associability declines as it becomes a more accurate predictor of subsequent events (or no event). By contrast, Wagner (1979) suggested that cue associability declines during preexposure, as the cue becomes better predicted by contextual and other stimuli, in the same way that, within the Rescorla and Wagner (1972) model, the formation of CS $\rightarrow$ US associations gradually reduces the effectiveness of the US on conditioning trials. Another approach is to posit that the stimulus forms associations with a "no event" representation or the experimental context, which interferes with the subsequent acquisition (or performance) of associations with an explicit event (e.g., Bouton, 1993; Miller \& Schachtman, 1985) in the training test phase. Yet another outlook considers the latent inhibition task within a broader, statistical framework, in which learning is construed as a recursive Bayesian inference problem. In this inference problem, both beliefs about the CS $\rightarrow$ no US and CS $\rightarrow$ US relations encountered (loosely, associative strengths) and the uncertainty of those beliefs (represented as associabilities) change over the course of the preexposure and test phases (e.g., Dayan,
Kakade, \& Montague, 2000). Extended preexposure results in reduction in uncertainty and hence cue associability, such that more evidence for the $\mathrm{CS} \rightarrow \mathrm{US}$ relation is needed to drive those associabilities high enough to permit to acquisition of a representation of that relation.

\section{Training procedure determines effects of preexposure}

Our observation that identical preexposure conditions led to different outcomes depending on the nature of the training tests indicates that variations in how preexposure learning is expressed during the training test are critical determinants of latent inhibition (or facilitation) effects. A reasonable starting point is to note that in most cases, latent inhibition was greater the more similar the preexposure and training test situations were. Indeed, this observation is consistent with the widely observed outcome that latent inhibition is context dependent. Many experiments (e.g., Bouton 1993; Hall \& Channell, 1985; Lovibond et al., 1984) show that conducting preexposure and training test phases in physically different experimental chambers eliminates latent inhibition. Consequently, most latent inhibition theories have proposed some mechanism for context specificity. Wagner's (1979) theory provided the most straightforward account: Presentation of the preexposed CS in a new context would restore its salience, because it would no longer be signaled by the contextual cues. Other theories essentially either declare their latent inhibition mechanism to be context dependent or embed that mechanism within some representation of context (e.g., Bouton, 1993; Gluck \& Myers, 1993). For example, if an animal is attempting to integrate the $\mathrm{CS} \rightarrow$ no event and $\mathrm{CS} \rightarrow$ sucrose experiences to establish or perform new associations, or to form an estimate of the likelihood of current reinforcement, weighting of the former experiences would be reduced the more distinguishable the preexposure and test contexts, reducing the magnitude of latent inhibition. Although in our experiments, the chambers were never altered, procedural differences between preexposure and test phases could all be construed as inducing contextual change. For example, whereas preexposure occurs in a context of nonreinforcement, the training test involves a context of sucrose reinforcement. Indeed, the inclusion of unpaired reinforcers in the preexposure period (but not paired with the target stimulus) generally enhances latent inhibition (Killcross, 1996), although that effect could instead be attributed to additional conditioning of true inhibition. Likewise, the common observation of smaller latent inhibition effects when larger USs are used in the test phase (e.g., Rodríguez \& Alonso, 2004) could be interpreted as the consequence of greater differentiation between preexposure and test contexts.

In our experiments, the inclusion (or exclusion) of other events in the preexposure or training test phases could also be construed as contextual changes. For example, adding a 
second test cue of the same modality as the preexposed stimulus (Experiment 2) might reduce the magnitude of latent inhibition compared to a procedure in which only the preexposed cue was tested. Although this comparison was not made explicitly in the present experiments, it is perhaps worth noting that the $\mathrm{N} / \mathrm{N}+$ procedure in Experiment 3 (Figs. 5 and 6) produced the numerically largest latent inhibition effect across studies. Adding a CS of another modality might then produce an even greater context change, and should further reduce latent inhibition (as was the case in comparing Experiment 2 with Experiment 1, in which facilitation was observed). Likewise, removing a cue that was present in preexposure (as in the NP/N+ condition of Experiment 3) reduced latent inhibition, and including an additional cue in both preexposure and training test phases $(\mathrm{NP} / \mathrm{NP}+$ treatment in Experiment 3) enhanced latent inhibition, compared to treatments in which a cue was included in one phase but not the other (N/NP+ and NP/N+ in Experiment 3). Finally, the use of a relatively nonsalient context, as in the weak condition in Experiment 4, might make the difference in reinforcement context across preexposure and training test phases more obvious, and hence reduce latent inhibition.

\section{Observation of facilitatory preexposure effects}

None of these approaches to understanding latent inhibition anticipates the observation of the opposite, facilitatory, effects of preexposure in Experiments 1, 3, and 4. A critical initial question is how learning about the stimulus in preexposure could be manifested in opposite ways in a subsequent test. Perhaps the simplest possibility is that preexposure learning is complex and includes components that slow, and others that speed, subsequent learning. Variations in the test procedures select which of these components is more influential. For example, preexposure might reduce attention to a cue, which might both slow subsequent associative learning about it and habituate unconditioned ORs to it. If those ORs normally compete with the measure of associative learning (either in performance or in new learning), then preexposure could appear to facilitate that learning. At first glance, such an account might embrace the apparently opposite results of Experiments 1 and 2. In Experiment 1, habituation of an OR to a cue of one modality would be unlikely to generalize to a qualitatively different OR that occurs to a cue of another modality. Thus, although acquisition of food-cup responding to the preexposed CS would be freed from competition from ORs, acquisition to the novel cue would suffer from it, yielding an apparent facilitation of learning by preexposure. By contrast, in Experiment 2, generalization of such habituation might be substantial between cues that share a modality (and an OR). Thus, there might be relatively little competition from ORs for either preexposed or novel CSs, permitting the display of more specific learning of inattention (for example) to the preexposed cue as latent inhibition. In support of this possibility, the preexposed versus novel difference in the activity response during the last half of the CS-US interval (when facilitation and latent inhibition of food-cup responding were largest) appeared larger in Experiment 1 than in Experiment 2. On the other hand, the same release from OR competition observed in Experiment 1 should be observed in a training test in which only a single CS was presented. But both the $\mathrm{N} / \mathrm{N}+$ procedure in Experiment 3 and the $\mathrm{S} / \mathrm{N}$ procedure in Experiment 4 produced latent inhibition, whereas facilitation was observed in Experiment 1. Similarly, neither the effects of preexposure-test similarity in Experiment 3 nor the effects of context salience in Experiment 4 seem readily interpretable in this fashion, because the opportunities for OR competition were identical across conditions, but food-cup outcomes ranged from latent inhibition to facilitation.

Within the OR competition view just described, facilitation is construed as an artifact. An alternate view is that facilitation, like latent inhibition, is a normal consequence of stimulus preexposure, involving, for example, constructing a more detailed, accurate, or consistent CS representation, which is more readily associated with USs (Gibson \& Walk, 1956; Rescorla \& Holland, 1976; see also accounts for the immediate shock deficit, e.g., Fanselow, 1986; Rudy \& O’Reilly, 1999, in which exposure to contexts enhances subsequent fear conditioning, perhaps by allowing formation of a more detailed context representation). Manipulations such as those used in the present experiments might affect the amounts of either preexposure consequence. Unfortunately, there are few accounts for facilitatory outcomes, or how more accurate representations of stimuli as simple as tones and lights could speed subsequent learning. Recent accounts for "perceptual learning" effects, in which prior exposure to a pair of cues enhances subsequent discrimination learning between them, assume that in the preexposure phase, elements common to both stimuli lose their effectiveness (as in latent inhibition) more rapidly than unique elements because they presented more frequently (e.g., McLaren et al., 1990). This loss in the associability of the common elements encourages learning about the unique features of those cues in the training test, thus enhancing the rate of discrimination learning. However, in the present experiments, all cues presented in the training test were reinforced, so it is difficult to see how differences in the distribution of conditioning among unique and common elements would yield facilitated learning.

Learning theories that include a major role for stimuli that occur outside particular learning trials may prove more amenable to providing accounts for our results. For example, Schmajuk et al. (1996) suggested that learning rates are affected both by attention to a cue and overall levels of novelty. Preexposure of a stimulus reduces both attention to it and its individual novelty, lowering its learning rate parameter. By contrast, changing contexts, or adding or deleting stimuli from 
the preexposure context, all increase learning rates, by increasing total novelty. In principle, these increases might offset losses induced by preexposure and even yield facilitation if the gain from enhancing overall novelty is greater than the net loss from reducing the novelty of and attention to the preexposed cue.

Likewise, a recent "latent cause" model of conditioning, which attempts to recover the full generative process giving rise to all stimuli, not just USs, may also provide a more promising perspective (Courville, 2006; Courville, Daw, \& Touretzky, 2006). Within this model, a variety of latent causes, each with a weight connecting to every stimulus, may appear and disappear as different events are experienced. With a simple, one stimulus (e.g., $\mathrm{N} / \mathrm{N}+$ ) preexposure/training procedure, the most likely inferred model structure would be a single latent cause, spanning both preexposure and training test phases. In that case, latent inhibition would occur because the preexposure phase would reduce the weight uncertainty such that more evidence would be required in the training test phase to drive the weights up sufficiently for CR acquisition. However, within this model, any surprising stimulus event, either omission of an expected event or presentation of an unexpected stimulus, could in principle lead to increases in cue uncertainty, enhancing learning rates. Thus even introduction of an unexpected neutral stimulus (e.g., Blaisdell, Bristol, Gunther, \& Miller, 1998) or omission of an expected neutral stimulus (Wilson, Boumphrey, \& Pearce, 1992; Holland \& Schiffino, 2016) might induce faster learning, reversing latent inhibition, and potentially enhancing learning outright.

However, it is difficult to see how either novelty effects (Schmajuk et al., 1996) or induction of new latent causes (Courville, 2006; Courville et al., 2006) could produce facilitation of learning about a preexposed cue compared to learning about a novel cue, as in Experiment 1. Both the novel and preexposed cues would have benefited from the same overall novelty increases or context changes, but the preexposed cue would still begin the training test with a lower individual learning rate parameter.

\section{Preexposure effects differed across measures of conditioning}

Although we observed a mix of latent inhibition and facilitation effects with our primary measure of conditioning, the time spent in the food cup during a CS, the activity measure uniformly showed latent inhibition. In an experiment in which rats received pairings of a visual CS with food delivery, Boughner and Papini (2003) reported that conditioning of approach to the visual CS (sign-tracking) was slowed by preexposure to that CS, but approach to the food cup (goal-tracking) was not. Because previous comparisons of video records and activity scores suggested that our activity measure in part reflected ORs elicited by the CSs (e.g., El-Amamy \& Holland, 2007;
Groshek et al., 2005; Holland, 1977; Holland, 2014), it could easily be argued that our results replicate their suggestion that sign tracking is more sensitive to latent inhibition than goal tracking. Likewise, they noted that whereas goal-tracking responses exhibited typical acquisition functions, only their preexposed rats showed such functions for sign-tracking responses, with nonpreexposed rats maintaining a high initial response probability throughout the training test, patterns that were also observed in some of our experimental conditions.

As we suggested in Experiment 1, Boughner and Papini (2003) noted that their sign tracking functions might reflect a combination of habituation of unconditioned approach responses to the visual stimulus and acquisition of conditioned stimulus approach (sign-tracking) responses. Thus, it is possible that the apparent latent inhibition of the conditioning of cue-directed responses was in fact more reflective of habituation of unconditioned cue-directed responses (cf. Hall \& Schachtman, 1987). That possibility would be consistent with our observation of comparable "latent inhibition" with the activity measure across the procedural/contextual manipulations that influenced the magnitude and direction of preexposure effects with the time in food-cup measure. Unlike latent inhibition, habituation is seldom context dependent (Hall \& Honey, 1989; Marlin \& Miller, 1981), and considerable data from our laboratory show that the brain determinants of the acquisition of conditioned ORs to the visual and auditory CSs used in these studies are often independent of those of the elicitation or habituation of unconditioned ORs to those stimuli (Baxter et al., 1997; Han et al., 1995). It is notable that a similar confound might exist in many other studies of latent inhibition in which unconditioned responses to novel CSs are similar to CRs established by pairings with a US. For example, in studies with shock USs, conditioned suppression might easily be confused with unconditioned suppression elicited by many CSs prior to conditioning, or pseudoconditioned responses to those CSs consequent to the simple presentation of the US within the experimental context, even without pairing with the CS.

Boughner and Papini (2003) also offered the related possibility that habituation of CS-approach responses reduced their operant level such that when reinforcement was introduced in the training test, there was much less opportunity for instrumental reinforcement of those behaviors than would have occurred in the nonpreexposed rats. As a result, preexposure might change the form of conditioned responding more than the ease of learning in general. Thus, in principle preexposure could result in either facilitation or latent inhibition effects, depending on the responses monitored in the training test. However, as with the previously suggested OR habituation account, it is not clear how this approach would deal with the results of Experiments 3 or 4.

Although we have consistently reported the time spent in the food cup as our primary measure of appetitive learning, 
many (if not most) investigators instead report the rate of foodcup entry, perhaps because of its similarity to rate measures usually reported in operant learning experiments. Thus, it is informative to compare the outcomes with these two measures. When the time in food-cup measure showed significant facilitation, in most cases the food-cup entry rate revealed no difference between responding in preexposed and nonpreexposed conditions, but showed marginally significant facilitation in one case (Experiment 1) and significant latent inhibition in another (Group NP/N+ in Experiment 3). On the whole, the rate measure seemed to be less sensitive to experimental manipulations and show smaller effect sizes than the time measure. This lower sensitivity is consistent with our lengthy experience with these measures, and was the basis for our selecting the time measure as the primary index of conditioning in this preparation in the first place; rats often remain in the food cup after their initial entries (see Holland, Lamoureux, Han, \& Gallagher, 1999, for an exception).

In most of these experiments, the preexposure effects on food-cup behaviors, either latent inhibition or facilitation, were larger during the last half of the CS-US interval than during the first half, and the latent inhibition effects on activity tended to be larger during the first half. These differences most likely track the normal temporal distribution of these behaviors, with food-cup behavior occurring closer to the time of sucrose delivery, and activity occurring closer to the time of CS onset (Holland, 1977, 1980). It is perhaps worth noting that in the case of latent inhibition outcomes with the food-cup time measure, an implication of this pattern is that the rats tended to show less difference in responding between first and last halves of a preexposed CS than of a nonpreexposed CS, the opposite of the effect reported recently by Bonardi et al. (2016).

The fact that rather minor manipulations yielded diverse outcomes in the present experiments suggests that preexposure might interact with other, more complex training procedures in unexpected ways. Our observation that the consequences of CS preexposure for subsequent learning about that CS can vary considerably across preexposure and test conditions as well as response measures has implications for our theories of the nature of preexposure effects and for attempts to use the latent inhibition paradigm to inform us about, or as a diagnostic tool for, human psychopathology (e.g., Baruch, Hemsley, \& Gray, 1988; Gray, Hemsley, \& Gray, 1992; Lubow \& Gewirtz, 1995; Lubow \& Weiner, 2010; Moser, Hitchcock, Lister, \& Moran, 2000).

\section{References}

Baruch, I., Hemsley, D. R., \& Gray, J. A. (1988). Differential performance of acute and chronic schizophrenics in a latent inhibition task. Journal of Nervous \& Mental Disease, 176, 598-606.
Baxter, M. G., Holland, P. C., \& Gallagher, M. (1997). Disruption of decrements in conditioned stimulus processing by selective removal of hippocampal cholinergic input. Journal of Neuroscience, 17, 5230-5236.

Blaisdell, A. P., Bristol, A. S., Gunther, L. M., \& Miller, R. R. (1998). Overshadowing and latent inhibition counteract each other: Support for the comparator hypothesis. Journal of Experimental Psychology: Animal Behavior Processes, 24, 335-351.

Bonardi, C., Brilot, B., \& Jennings, D.J. (2016). Learning about the CS during latent inhibition: Preexposure enhances temporal control. Journal of Experimental Psychology: Animal Learning and Cognition, 42, 187-199.

Boughner, R. L., \& Papini, M. R. (2003). Appetitive latent inhibition in rats: Now you see it (sign tracking), now you don't (goal tracking). Learning \& Behavior, 31, 387-392.

Bouton, M. E. (1993). Context, time, and memory retrieval in the interference paradigms of Pavlovian conditioning. Psychological Bulletin, 114, 80-99.

Channell, S., \& Hall, G. (1983). Contextual effects in latent inhibition with an appetitive conditioning procedure. Animal Learning \& Behavior, 11, 67-74.

Chiba, A. A., Bucci, D. J., Holland, P. C., \& Gallagher, M. (1995). Basal forebrain cholinergic lesions disrupt increments but not decrements in conditioned stimulus processing. Journal of Neuroscience, 15, $7315-7322$.

Courville, A. C. (2006). A latent cause theory of classical conditioning (Doctoral dissertation, Carnegie-Mellon University, Pittsburgh, PA).

Courville, A. C., Daw, N. D., \& Touretzky, D. S. (2006). Bayesian theories of conditioning in a changing world. Trends in Cognitive Sciences, 10, 294-300.

Dayan, P., Kakade, S., \& Montague, P. R. (2000). Learning and selective attention. Nature Neuroscience, 3, 1218-1223.

El-Amamy, H., \& Holland, P.C. (2007). Dissociable effects of disconnecting amygdala central nucleus from the ventral tegmental area or substantia nigra on learned orienting and incentive motivation. European Journal of Neuroscience, 25, 1557-1567.

Fanselow, M. S. (1986) Associative vs. topographical accounts of the immediate shock freezing deficit in rats: Implications for the response selection rules governing species specific defensive reactions. Learning and Motivation, 17, 16-39.

Gibson, E. J., \& Walk, R. D. (1956). The effect of prolonged exposure to visually presented patterns on learning to discriminate them. Journal of Comparative and Physiological Psychology, 49, 239-242.

Gluck, M., \& Myers, C. (1993). Hippocampal mediation of stimulus representation: A computational theory. Hippopcampus, 3, 491516.

Gray, N. S., Hemsley, D. R., \& Gray, J. A. (1992). Abolition of latent inhibition in acute, but not chronic, schizophrenics. Neurology, Psychiatry, \& Brain Research, 1, 83-89.

Groshek, F., Kerfoot, E., McKenna, V., Polackwich, A. S., Gallagher, M., \& Holland, P. C. (2005). Amygdala central nucleus function is necessary for learning, but not expression, of conditioned auditory orienting. Behavioral Neuroscience, 119, 202-212.

Hall, G., \& Channell, S. (1985). Differential effects of contextual change on latent inhibition and on the habituation of an orienting response. Journal of Experimental Psychology: Animal Behavior Processes, $11,470-481$.

Hall, G., \& Honey, R. C. (1989). Contextual effects in conditioning, latent inhibition, and habituation: Associative and retrieval functions of contextual cues. Journal of Experimental Psychology: Animal Behavior Processes, 15, 232-241.

Hall, G., \& Schachtman, T. R. (1987). Differential effects of a retention interval on latent inhibition and the habituation of an orienting response. Animal Learning \& Behavior, 15, 76-82. 
Han, J. S., Gallagher, M., \& Holland, P. C. (1995). Hippocampal lesions disrupt decrements but not increments in conditioned stimulus processing. Journal of Neuroscience, 15, 7323-7329.

Holland, P. C. (1977). Conditioned stimulus as a determinant of the form of the Pavlovian conditioned response. Journal of Experimental Psychology: Animal Behavior Processes, 3, 77-104.

Holland, P. C. (1980). CS-US interval as a determinant of the form of Pavlovian appetitive conditioned responses. Journal of Experimental Psychology: Animal Behavior Processes, 6, 155-174.

Holland, P.C. (2014). Relations between automated activity counts and observed rearing in intact rats and rats with lesions of dorsolateral striatum. Unpublished analyzed data.

Holland, P. C., \& Gallagher, M. (1993). Amygdala central nucleus lesions disrupt increments, but not decrements, in conditioned stimulus processing. Behavioral Neuroscience, 107, 246-253.

Holland, P. C., Lamoureux, J. A., Han, J. S., \& Gallagher, M. (1999). Hippocampal lesions interfere with negative occasion setting. Hippocampus, 9, 143-157.

Holland, P. C., \& Schiffino, F. L. (2016). Mini-review: Prediction errors, attention and associative learning. Neurobiology of Learning and Memory, 131, 207-215.

Kellman, P. J., \& Massey, C. M. (2013). Perceptual learning, cognition, and expertise. Psychology of Learning and Motivation, 58, 117-165.

Killcross, A. S. (1996). Contextual control of latent inhibition by the reinforcer. Quarterly Journal of Experimental Psychology, 49B, 45-59.

Lovibond, P. F., Preston, G. C., \& Mackintosh, N. J. (1984). Context specificity of conditioning, extinction, and latent inhibition. Journal of Experimental Psychology: Animal Behavior Processes, $10,360-375$.

Lubow, R. E., \& Gewirtz, J.C. (1995). Latent inhibition in humans: Data, theory, and implications for schizophrenia. Psychological Bulletin, 117, 87-103.

Lubow, R. E., \& Moore, A. U. (1959). Latent inhibition: The effect of nonreinforced preexposure to the conditioned stimulus. Journal of Comparative and Physiological Psychology, 52, 415-419.

Lubow, R. E., Schnur, P., \& Rifkin, B. (1976). Latent inhibition and conditioned attention theory. Journal of Experimental Psychology: Animal Behavior Processes, 2, 163-174.

Lubow, R. E., \& Weiner, I. (2010). Latent inhibition: Cognition, neuroscience, and applications to schizophrenia. New York: Cambridge University Press.

Marlin, N. A., \& Miller, R. R. (1981). Associations to contextual stimuli as a determinant of long-term habituation. Journal of Experimental Psychology: Animal Behavior Processes, 1, 313-333.
McLaren, I. P. L., Kaye, H., \& Mackintosh, N. J. (1990). An associative theory of the representation of stimuli: Applications to perceptual learning and latent inhibition. In R. G. M. Morris (Ed.), Parallel distributed processing: Implications for psychology and neurobiology (pp. 102-130). New York: Oxford University Press.

Miller, R. R., \& Schachtman, T. R. (1985). The several roles of context at the time of retrieval. In P. D. Balsam \& A. Tomie (Eds.), Context and learning (pp. 167-194). Hillsdale, NJ: Erlbaum.

Moser, P. C., Hitchcock, J. M., Lister, S., \& Moran, P. M. (2000). The pharmacology of latent inhibition as an animal model of schizophrenia. Brain Research Reviews, 33, 275-307.

Pearce, J. M., \& Hall, G. (1980). A model for Pavlovian learning: Variations in the effectiveness of conditioned but not of unconditioned stimuli. Psychological Review, 87, 532-552.

Rescorla, R. A. (1988). Behavioral studies of Pavlovian conditioning. Annual Review of Neuroscience, 11, 329-352.

Rescorla, R. A., \& Holland, P. C. (1976). Some behavioral approaches to the study of learning. In E. Bennett \& M. R. Rozensweig (Eds.), Neural mechanisms of learning and memory (pp. 165-192). Cambridge, MA: MIT Press.

Rescorla, R. A., \& Wagner, A. R. (1972). A theory of Pavlovian conditioning: Variations in the effectiveness of reinforcement and nonreinforcement. In A. H. Black \& W. F. Prokasy (Eds.), Classical conditioning II (pp. 64-99). New York, NY: AppletonCentury-Crofts.

Rodríguez, G., \& Alonso, G. (2004). Latent inhibition as a function of US intensity in a two-stage CER procedure. Psicológica, 25, 207-216.

Rodríguez, G., Alonso, G., \& Hall, G. (2015). Effects of stimulus salience on the magnitude of latent inhibition after compound conditioning. Journal of Experimental Psychology: Animal Learning and Cognition, 41, 378-384.

Rudy, J. W., \& O'Reilly, R. C. (1999). Contextual fear conditioning, conjunctive representations, pattern completion, and the hippocampus. Behavioral Neuroscience, 113, 867-880.

Schmajuk, N. A., Lam, Y.-W., \& Gray, J. A. (1996). Latent inhibition: A neural network approach. Journal of Experimental Psychology: Animal Behavior Processes, 22, 321-349.

Wagner, A. R. (1979). Habituation and memory. In A. Dickinson \& R. A. Boakes (Eds.), Mechanisms of learning and motivation. Hillsdale, NJ: Erlbaum.

Wilson, P. N., Boumphrey, P., \& Pearce, J. M. (1992). Restoration of the orienting response to a light by a change in its predictive accuracy. Quarterly Journal of Experimental Psychology, 44B, 17-36. 